\title{
CÍRCULOS SOCIALES, CONTEXTOS NORMATIVOS Y CRÉDITO. BUENOS AIRES, SIGLO XVII
}

\author{
SOCIAL CIRCLES, NORMATIVE FRAMEWORKS \\ AND CREDIT. BUENOS AIRES, 17TH CENTURY
}

\author{
Martín L. E. Wasserman* \\ Universidad de Buenos Aires, Buenos Aires, Argentina, <wassermanmle@gmail.com>
}

Resumen. El presente artículo se propone indagar en los órdenes normativos, círculos de sociabilidad y dispositivos institucionales a los cuales los actores apelaban para interactuar económica y comercialmente en Buenos Aires durante la primera mitad del siglo XVII. Recurriendo al endeudamiento interpersonal como observatorio, se avanzará en la comprensión de la práctica consistente en formalizar legalmente, ante el escribano, las obligaciones derivadas de las deudas. Mediante este abordaje se intentará indagar en el peso que las redes de parentesco detentaron como uno de los órdenes normativos e institucionales posibles para la interacción económica del temprano Río de la Plata.

Palabras clave: círculos de sociabilidad, instituciones, redes, crédito.

Abstract. This article aims to investigate the normative orders, sociability circles and institutional arrangements that actors used for their economic and commercial interaction during the first half of the 17th century in Buenos Aires. By studying interpersonal borrowing as observatory, we will advance in understanding the practice of registering the debts with the notary. Through this approach we will try to investigate the actual weight of the interpersonal networks as one of the institutional and normative contexts available for economic interaction in the early Rio de la Plata.

Key words: sociability circles, institutions, networks, credit.

Fecha de recepción: abril de 2012. Fecha de aceptación: junio de 2012.

* Agradezco a los evaluadores anónimos por los enriquecedores comentarios, sugerencias y señalamientos que me han provisto tras sus atentas lecturas a una primera versión de este trabajo. Igualmente valiosas han resultado las observaciones provistas por la doctora Guillermina del Valle Pavón.

Am. Lat. Hist. Econ., año 20, núm. 1, enero-abril, 2013, pp. 35-77 


\section{INTRODUCCIÓN}

$\mathrm{E}$ 1 presente artículo tiene como objetivo principal indagar en qué medida los tratos crediticios, puntales del comercio y la circulación, se apoyaban en redes de parentesco ante un contexto como el de Buenos Aires durante el temprano siglo XVII. Ello conducirá a reflexionar sobre la participación que las redes de parentesco y los contratos legales tuvieron como estructuras institucionales para la interacción económica en la circulación comercial hispanoamericana. Para ello, analizaremos el lugar que ocupaban en la economía las transacciones crediticias escrituradas ante el notario, a los efectos de discernir en qué instancias de la interacción económica, los actores apelaban al orden normativo dispuesto por la letra de los contratos y en qué medida esta estructura normativa se yuxtaponía con la ofrecida por los círculos de sociabilidad próximos. Nuestra hipótesis sostiene que las redes de parentesco, medulares para la organización central de las empresas comerciales y para el acceso al crédito en esa instancia de los negocios, carecían del mismo peso como articuladoras de las redes en las instancias subsecuentes de los negocios, constituidas por operaciones de menor escala que también precisaban de crédito.

Tal como lo ha señalado la historiografía, se revela necesario un análisis que compense el escaso conocimiento sobre los mecanismos empleados por los comerciantes para llevar adelante sus transacciones ante contextos de riesgo e incertidumbre, atendiendo a las opciones que para ello proveía el marco institucional: redes interpersonales y transacciones mercantiles tienden a presentarse como los extremos de tales alternativas institucionales. ${ }^{1}$ En la América Latina colonial el orden jurídico era lo suficientemente endeble para ofrecer instrumentos que garantizasen la previsión en la arena del comercio y de las relaciones crediticias que lo sostenían. ${ }^{2}$ Una consecuencia primordial consistió en la necesaria conformación de redes sostenidas en la confianza, articuladas preferentemente sobre el parentesco, como modo de afrontar los negocios. ${ }^{3}$ ¿Se carecía, entonces, de estruc-

1 Álvarez, "Mercados", 2011, pp. 53-54.

${ }^{2}$ Véanse Barriera y Tarragó, "Elogio", 2003, p. 192, y Moutoukias, "Familia”, 2000, p. 151.

${ }^{3}$ Véanse Kicza, Empresarios, 1986, y Lindley, Kinship, 1976. Asimismo, véase el modélico caso analizado por Del Valle, en donde se explica "cómo la constitución de la fortuna y los negocios de Manuel Rodríguez de Pedroso se basaron, fundamentalmente, en las relaciones familiares que entretejió". Valle, "Relaciones", 2007, p. 136. El reconocido número del Anuario del Instituto de Estudios Histórico-Sociales editado en 2000 y dedicado al análisis de los grupos sociales, recoge reflexiones valiosas al respecto. Así, Jean-Paul Zúñiga explicaba que la centralidad de ciertos individuos podía derivar de su capacidad de hacer circular dinero, servicios o influencias " $a$ través de las relaciones familiares en las que se encuentran sumidos", en Zúñiga, "Clan”, 2000, p. 56, cursivas mías; en tanto que la familias de índole de los Campa Cos, como señalara Langue, constituyeron un modelo de organización económica sostenida sobre la base de extensas redes de solidaridades, 
turas contractuales para configurar legalmente los tratos crediticios? ${ }^{4} \mathrm{De}$ haberse contado con estructuras contractuales, ¿resultaron prescindibles?, ¿en qué instancia de los negocios se ponían en práctica?, ¿movilizaban sumas marginales?, ¿̇en qué medida los contratos se apoyaban sobre redes de parentesco, en una ciudad-puerto marginal y arriesgada como lo fue Buenos Aires durante el siglo XVII ${ }^{5}$

\section{REDES DE PARENTESCO, CONTRATOS NOTARIALES Y NEGOCIOS}

La historiografía ha demostrado que en el espacio latinoamericano del antiguo régimen, los negocios podían y solían organizarse a través de estructuras relacionales en las que los lazos familiares, sin excluir otros tipos de lazos e incorporando en su seno el parentesco en sentido amplio, ocuparon un lugar primordial. ${ }^{6}$

Las redes de vínculos primarios se presentaban como sustrato relacional de la organización de los negocios comerciales. ${ }^{7}$ La necesidad de establecer vínculos mediante el endeudamiento (desde el crédito monetario y las ventas a fiado hasta la fundamental consignación de mercancías para su comercialización en otras plazas) volvía imperioso el despliegue de mecanismos tendentes a una minimización del riesgo en los tratos comerciales. Ello conducía a estrategias de previsión que reposaban, en buena medida, sobre la creación de necesidades recíprocas que trascendiesen lo inmediato. De esta manera la construcción de lazos primarios puede comprenderse tanto como la diversificación de actividades, en términos de estrategias orientadas a mermar el riesgo en los negocios y el comercio, riesgos que

en Langue, "Elites", 2000, p. 105. Referiremos a otros artículos de dicha publicación a lo largo del artículo.

${ }^{4}$ Moutoukias ha explicado la consecuente "ausencia de estructuras contractuales que reglaran la cooperación a largo plazo para la organización de los negocios”, véase Moutoukias, "Redes", 1992, p. 10.

${ }^{5}$ Atendemos al medular señalamiento de Moutoukias, quien propuso considerar el papel que simultáneamente desempeñaron los lazos fuertes y débiles para reconocer a la familia como una unidad inscrita en un conjunto más amplio: "es necesario reconstruir la dinámica del conjunto para comprender el papel de esos vínculos primarios", en Moutoukias, "Familia", 2000, p. 143.

${ }^{6}$ Véase Bertrand, “Actor”, 2009.

${ }^{7}$ Moutoukias ha reconocido que las redes obraban como marcos institucionales para la organización de los negocios, sosteniéndolos en contratos implícitos o tácitos que se establecían en el interior de un tejido de vínculos primarios, cuyas relaciones de poder aseguraban el cumplimiento de esos mismos tratos. En ese mismo escrito, el autor señalaba asimismo la importancia "del papel de las normas, así como el del fascinante aspecto de la gestión simultánea de normatividades heterogéneas", que quedaba afuera de los límites de su trabajo. "Un ejemplo del interés que tendría un estudio de este aspecto lo constituye el hecho de que una buena parte de la información presentada surge de documentos que constituyen verdaderos compromisos contractuales escritos." Moutoukias, "Contrabandistas", s. a., pp. 15-16. 
el sistema jurídico no podía atenuar. ${ }^{8}$ A diferencia de otros puntos del imperio hispano, como Lima o México, que representaban núcleos estratégicos del comercio, Buenos Aires no contó con un Consulado de Comercio hasta fines del siglo XVIII. ${ }^{9}$ Expresión de la marginalidad legal que Buenos Aires revestía en relación con la carrera de Indias durante el siglo XVII, los tratos comerciales carecían en este puerto de aquella institución que proveyese un marco normativo ajustado a la dinámica del comercio, con facultades para ejercer una justicia privativa desde un tribunal mercantil y enfrentar, desde este instrumento corporativo, las dificultades para efectivizar el cobro de deudas ante los riesgos implicados en la dilación y azar de las expediciones comerciales entre el puerto y otras regiones, o la abierta defraudación. ${ }^{10}$ La construcción de relaciones confiables, atravesadas por la lealtad, la dependencia, los vínculos afectivos y la autoridad interpersonal, proveía entonces un capital relacional mediante el cual se organizaban los negocios con un margen mayor de previsión. ${ }^{11}$

El parentesco espiritual provisto por el compadrazgo sacramental constituía, tanto como los lazos de sangre, un "terreno seguro sobre el cual se edificaron relaciones duraderas e irreversibles", ${ }^{12}$ razón por la cual estas redes de vínculos primarios, con sus núcleos en la parentela, "representaban el principal recurso para organizar negocios o empresas personales". ${ }^{13}$ Este círculo de lazos primarios proveía a los actores con un entorno relacional íntimo, en el cual los mecanismos del enlace espiritual públicamente reconocido ofrecían un contexto de confianzas para desplegar negocios.

Tal como señalan Alfani y Gourdon en trabajos recientes, el parentesco espiritual permitía establecer redes de solidaridad entre sujetos con intereses complementarios o involucrados en una misma actividad, así como entre mercaderes que mediante este lazo ritual buscaban proteger sus relaciones de negocios. Era, en efecto, un modo de formalizar institucionalmente la relación para sujetar a los involucrados a reglas de conduc-

\footnotetext{
${ }^{8}$ Como explica Levi, las estrategias de relaciones son parte de las técnicas del control del medio, orientadas a mejorar la previsibilidad para aumentar la seguridad. Levi, Herencia, 1985, pp. 61-62.

${ }^{9}$ El mismo sería fundado recién hacia 1794 , resultado de un proceso de constitución de Juntas de Comercio que desde 1779 adquirieron "estabilidad y representatividad de toda la corporación” de los comerciantes. Kraselsky, “Juntas”, 2007.

${ }^{10}$ Véase Valle, "Comercio", 2001.

${ }^{11}$ Barriera y Tarragó, "Elogio", 2003, y "Vínculo", 2000. En este sentido, "la inseguridad no procede sólo de la dificultad de prever el futuro, sino también de la continua consciencia de disponer de informaciones limitadas sobre las fuerzas operantes en el medio social”, en Levi, Herencia, 1985 , p. 61.

${ }_{12}$ Reitano, "Portugueses", 2003, p. 203.

${ }^{13}$ Ibid., p. 204.
} 
ta y cargas mutuas, imponiendo la abstención sobre acciones moralmente condenables. $^{14}$

De este modo, instituciones sociales tales como el compadrazgo, protegiendo la relación de negocios mediante el ritual público y el escrutinio sagrado, permitían realizar transacciones con menores costos de transacción que los implicados en la apelación a otras instituciones, tales como la realización de complejos contratos, legalmente escriturados ante el notario, para configurar obligaciones de pago derivadas de anticipos o préstamos. ${ }^{15}$

Esto nos conduce a reconocer que los contratos escriturados por el notario constituían otro dispositivo institucional, mediante el cual era posible estructurar las transacciones y sus correspondientes obligaciones en un contexto normativo dado. Sin intervenir habitualmente como parte contractual, el escribano instituía y proveía los mecanismos necesarios para la concreción de operaciones: información y escrituras. Dicha mediación, entendida no sólo como intervención activa para el establecimiento de contactos, sino como proveedora de los dispositivos contractuales sobre los cuales estructurarlos, hacía del escribano una institución adecuada para operar allí cuando el deudor era desconocido para el acreedor o cuando el conocimiento interpersonal entre ambos no bastaba para librar el trato al arreglo y arbitraje privado. El despacho de la escribanía pública y del Cabildo de Buenos Aires fungía entonces como una institución que contrapesaba la información asimétrica predominante en una población con fuerte movilidad demográfica. ${ }^{16}$ Enlazaba a potenciales tomadores y consignatarios dispuestos a asumir obligaciones, con acreedores dispuestos a confiar sus valores en aquellos a quienes no conocían directamente o cuya reputación no habían evaluado suficientemente. ${ }^{17}$

${ }^{14} \mathrm{El}$ compadrazgo sacramental implicaba el establecimiento público, in facie communitatis (frente a la comunidad), de una conexión entablada bajo escrutinio divino: quien con su conducta rompiese las reglas inherentes a esta conexión sacramental no sólo provocaba la ira de Dios, también incurría en sanciones sociales y en los daños económicos derivados de la desconfianza y de la pérdida de la honra. Ello hacía que el compadrazgo y el parentesco espiritual se revelasen útiles para aquellos que quisiesen iniciar negocios en una situación de información asimétrica o insuficiente, o en la cual las instituciones jurídicas no proveyesen la seguridad adecuada para garantizar el comportamiento esperado. Véanse Alfani, "Reformation", 2012, pp. 482-483, y Alfani y Gourdon, "Entrepreneurs", 2010.

${ }_{15}$ Alfani y Gourdon, "Entrepreneurs", 2010.

${ }^{16}$ Desde 1584 -año de la primera escritura conservada en el fondo Escribanías antiguas del Archivo General de la Nación, Argentina- hasta comienzos del siglo XVIII existió un único registro en la ciudad. El segundo registro pudo abrirse recién hacia 1707.

${ }^{17}$ Para una ciudad de antiguo régimen como París, en la cual la densidad poblacional superaba ampliamente a la de Buenos Aires de su periodo, los notarios fungían como intermediarios, "arranging large numbers of loans between borrowers and lenders who did not know one another. What rendered such impersonal lending possible (so economic theory fruitfully suggests) was the financial information the notaries possessed". Hoffman, Postel-Vinay y Rosenthal, "Information", 1999 , p. 71. 
A los efectos de discernir la función que detentaba la práctica de formalizar notarialmente las deudas, se nos revela fecunda una reconstitución de los círculos de sociabilidad detentados por los actores. ${ }^{18}$ Ello permite reconocer diferentes entornos relacionales, sostenidos por vínculos de naturaleza e intensidad distintas (grados de mutua implicación e incidencia sobre el comportamiento), ${ }^{19}$ formalizados mediante diversos dispositivos institucionales y alcanzados por órdenes normativos diferentes -aun yuxtapuestos en ciertos vínculos-, a través de los cuales un mismo actor despliega su acción. ${ }^{20}$ En vista de lo mencionado previamente, un primer círculo de sociabilidad estaba constituido por la unidad familiar, las amistades íntimas y la parentela espiritual en la que aquella unidad familiar se prolongaba. Un segundo círculo era constituido por socios económicos y partícipes de empresas o negocios en común que no reforzaban sus lazos mediante instituciones como la de compadrazgo o alianzas familiares. Un tercer círculo de sociabilidad, menos próximo y constituido por lazos establecidos con baja frecuencia, ofrece al actor un universo de contactos más distantes relacionalmente, de baja intensidad, externos a las redes de confianza y lealtad, sobre los que, sin embargo, podrá intentar la articulación de una "amistad instrumental" que, oportunamente, podrá capitalizar socialmente, es decir, incorporar a los primeros círculos de sociabilidad. ${ }^{21}$ La escritura notarial proveerá el dispositivo institucional para la formalización de estos lazos.

Los matrimonios y bautismos registrados en los libros parroquiales del Archivo Parroquial de Nuestra Señora de La Merced, ${ }^{22}$ en Buenos Aires, así como los documentos rescatados por Raúl Molina antes del incendio sufrido en buena parte del repositorio, ${ }^{23}$ nos permiten observar los vínculos

${ }^{18}$ No hablamos ya de redes de sociabilidad propiamente dichas, sino de "sistemas relacionales individuales, egocentrados y yuxtapuestos que descansan sobre el doble fundamento de las afinidades electivas y de las no electivas", en Bertrand, "Familia", 1999, p. 132.

${ }^{19}$ Véase Requena, “Concepto”, 1989, p. 145. Sostiene Granovetter que "nuestros conocidos ('lazos débiles') es menos probable que estén muy implicados socialmente entre sí que nuestros amigos íntimos ('lazos fuertes')". Es de este modo que "el conjunto de personas formado por un individuo y sus conocidos constituirá una red de baja densidad (donde muchas de las líneas posibles de relaciones están ausentes), mientras la red del conjunto formado por ese mismo individuo y sus amigos intimos estará tejida densamente (muchas de las líneas posibles están presentes)". Por lo tanto, "Ego tiene un conjunto de amigos íntimos, la mayoría de los cuales están en contacto entre sí; es decir, un 'grupo' densamente tejido de la estructura social. Además, Ego tiene un conjunto de conocidos, que sólo algunos de ellos se conocen mutuamente", en Granovetter, "Fuerza", 2003, pp. 196-197. Puede encontrarse en este modelo de Granovetter la distinción que sugerimos entre círculos primarios y secundarios de sociabilidad, con diferente incidencia sobre el comportamiento de los actores en función de la desigual densidad de los mismos.

${ }^{20} \mathrm{El}$ concepto de círculos sociales tiene en Simmel a su precursor, véase Simmel, Sociología, 1986, pp. 426, 434, 441-443.

${ }_{21}$ Bertrand, "Familia", 1999, pp. 130-132. Véase también Moutoukias, "Redes", 1992.

${ }^{22}$ Archivo Parroquial de Nuestra Señora de La Merced (en adelante APLM), Bautismos.

${ }^{23}$ Molina, Matrimonios, 2002. 
de parentesco ritual instaurados, y nos revelan asimismo ciertos espacios de sociabilidad común entre actores que no necesariamente se hallaban mutua y directamente vinculados. ${ }^{24} \mathrm{El}$ contraste y las intersecciones entre esos círculos sociales próximos y los lazos instituidos por deudas ante el notario, explicarán el papel que le correspondía a la práctica de formalizar legalmente las deudas en un contexto que sabía organizar sus negocios en redes interpersonales y en el cual el orden del derecho escrito carecía de mayor eficacia para regular los tratos. Observaremos a continuación, entonces, la estructura del crédito notariado durante una década clave para Buenos Aires: 1635-1644.

\section{RESTRICCIONES Y MOVILIDAD: LOS RIESGOS DE LA CIUDAD PORTUARIA}

Es conocido el peso que tuvieron las restricciones legales sobre Buenos Aires a poco de su refundación en 1580. El 28 de enero de 1594, como respuesta al descontento del comercio limeño ante los permisos concedidos para traficar por Buenos Aires, el rey prohibía la introducción por Río de la Plata de esclavos y mercancías que no fuesen conducidos mediante navíos despachados desde Sevilla por la Casa de Contratación. ${ }^{25} \mathrm{Al}$ poco tiempo, el 20 de agosto de 1602, el rey concedía una merced a los vecinos porteños para exportar a Brasil y Guinea, anualmente y en navíos propios, 2000 fanegas de harina, 500 quintales de cecina y 500 arrobas de sebo, prohibiéndose la exportación de plata y la importación de esclavos (pues sólo podía importarse, como retorno, "lienço calçado y otras cosas semejantes y fierro y açero"). ${ }^{26}$ Entre tanto, las importaciones debían consumirse en Río de la Plata, intentándose con ello cortar todo lazo que transformase a este en un puerto del interior para la salida de metálico. Desde entonces, la prohibición de exportar plata y de importar esclavos signará las concesiones graciosas otorgadas por el rey a los vecinos porteños. La merced real otorgada en 1602 había sido estipulada por un plazo de seis años. Vencida en 1608 , la corona procedió a sucesivas renovaciones hasta

\footnotetext{
${ }^{24} \mathrm{Tal}$ como señala Levi, es viable interpretar a las familias como "vínculos de parentesco consanguíneo o por alianzas o relaciones de parentesco ficticio, que aparecen, en la nebulosa realidad institucional del antiguo régimen, como cuñas estructuradas para afirmarse frente a la incertidumbre del mundo social, incluso tratándose de un pequeño pueblo". Es decir, "lazos que van más allá de la pura corresidencia”, en Levi, Herencia, 1985, pp. 56, 78. Puesto que uno de nuestros objetivos en este artículo consiste en discernir el lugar que esas cuñas estructuradas tuvieron en el crédito notariado, no realizaremos nuestro abordaje desde la reconstrucción de los frentes de parentesco, sino desde el conjunto de operaciones crediticias escrituradas y su contraste con los lazos del parentesco sacramental y consanguíneo. Ibid., pp. 166-167.

${ }^{25}$ Levillier, Audiencia, 1918-1922, t. III, p. 237.

${ }^{26}$ Archivo, Reales, 1911, t. I, pp. 52-53.
} 
que en 1618, informando desfavorablemente la Casa de Contratación con base en el descontento expresado por el Consulado de Sevilla, por real cédula del 8 de septiembre de ese año se otorgaba una última licencia con un plazo de vigencia limitado a tres años. ${ }^{27}$ Desde ese momento y hasta 1661 , no se conocen renovaciones de las mercedes otorgadas por la corona a los vecinos: ratificada en 1622 la real cédula de 1618, los navíos de registro pasarían a conformar el único cauce autorizado para la comercialización atlántica en Buenos Aires. ${ }^{28} \mathrm{El}$ tráfico de esclavos contaba, paralelamente, con el estrecho cauce del asiento, que abría y cerraba intermitentemente al puerto rioplatense la introducción legal de esclavos. ${ }^{29}$

Como puede observarse, las restricciones legales imponían la necesidad de construir redes confiables con las cuales transgredirlas, aun empleando cauces institucionalmente aceptados: arribadas, manifestaciones, denuncias, visitas, comisos y almonedas públicas fraudulentas, mecanismos en los cuales se veían implicadas las distintas instancias de la administración local. ${ }^{30}$ Pero cuando recordamos que la real cédula de 1618 dis-

${ }^{27}$ Permitía comerciar con Sevilla mediante dos navíos anuales de hasta 100 toneladas cada uno, propiedad de vecinos porteños (o fletados en Sevilla, oportunamente). Se autorizaba a recalar en la costa brasileña en el viaje de ida a Sevilla para la obtención de palo brasil y azúcar, prohibiéndose arribar en dicha costa durante el regreso a Río de la Plata. Conjuntamente, se disponía el establecimiento de una aduana en Córdoba que gravase las importaciones porteñas internadas al espacio económico peruano. Todo u otro comercio con Brasil o con otros puntos de intercambio sería tenido por contrabando. Ibid., pp. 116-117, y Jumar, "Commerce", 2000, p. 84.

${ }^{28}$ Los navíos de registro eran asimilables a los navíos sueltos que tocaban otros puertos externos al sistema de flotas y galeones.

${ }^{29}$ En 1595 se iniciaba el asiento concertado por la corona con Pedro Gómez Reynel, en el cual se le otorgaba facultad para ingresar 600 esclavos por Río de la Plata como monopolio exclusivo. En 1601 el asiento fue concedido a Joan Rodríguez Coutinho, habilitándosele asimismo la introducción por Río de la Plata de esclavos que, en esta oportunidad, provendrían de Angola. Hacia 1604 Gonzalo Váez Coutinho tomaba en sus manos el asiento esclavista que quedaba vacante por la muerte de su hermano Joan. Pero, desde este momento, Río de la Plata quedaba vedado al asentista como puerta para la introducción de las piezas, restringiéndose así los canales legítimos para el comercio atlántico de Buenos Aires. En 1618, por real cédula del 16 de abril, el asentista Antonio Rodríguez (o Fernández) Delvás conseguía que se le otorgase un permiso para introducir 450 esclavos por Río de la Plata durante un lapso de tres años. El asiento concretado en 1623 con Manuel Rodríguez Lamego volvía a excluir a Río de la Plata como acceso legítimo de los esclavos. Y recién en 1631, aún vigente el asiento de Lamego, el rey otorgaba una merced a su hermano el infante Fernando, arzobispo de Toledo, para introducir por Buenos Aires 1500 licencias de esclavos libres de derechos. El infante revendía casi inmediatamente dichas licencias a Nicolás Salvago, genovés residente en la corte de Madrid, quien al derrumbarse el tráfico marítimo en 1641 seguía administrando la introducción autorizada de esclavos por Río de la Plata, Archivo General de la Nación, Argentina (en adelante AGN), sala IX, Escribanías antiguas, t. XXI, 48-3-6, fs. 302r-303r; Scheuss, Trata, 1958, pp. 66, 93-95 y ss.; Vila, Hispanoamérica, 1977, pp. 3839, 41, y González, Pequeña, 2002, p. 76.

${ }_{30}$ Asimismo, una parte del comercio ilegal escapaba a todo mecanismo de fiscalización, gracias a la posibilidad de ocultar las embarcaciones en las islas San Gabriel o el uso de las chacras y estancias en calidad de desembarcaderos clandestinos para embarcaciones menores, por ejemplo. Véanse Moutoukias, “Forma”, 1991, p. 342, y González, Pequeña, 2002, p. 75. 
ponía que una de "las dos terçias partes" de las mercancías comisadas fuese destinada para el "denunciador", comprendemos que este contexto legalmente restrictivo ofrecía incentivos para que, ante desavenencias o contratiempos, los deudores externos a los círculos de sociabilidad próximos o débilmente inscritos en ellos, tirasen por la borda el corpus de reglas tácitas y sostenidas en la confianza.

Y los riesgos de la ilegalidad se estimulaban con una estructura poblacional sumamente móvil, en la cual las identidades personales de los tratantes no siempre eran mutuamente conocidas ni reconocidas. Tal como queda ilustrado en la gráfica 1, hacia la década de 1610 unos 2200 habitantes estables en Buenos Aires presenciaron el paso de una población flotante de 7800 personas (considerando viajeros, tripulantes, pasajeros, esclavos en tránsito, comerciantes del interior, mercaderes de ultramar, troperos de carretas, y soldados de paso). ${ }^{31}$ Hacia la década de 1620 unas 2400 personas afincadas testimoniaban el trajín de 6700 transeúntes. La población estable en la década de 1630, estimada en unas 3300 personas, atendía a una masa itinerante de 3100 personas. La brecha entre población estable y móvil se amplifica durante la primera mitad de la década de 1640 dada la irrupción sufrida por el comercio marítimo a partir de los conflictos iniciados en diciembre de 1640 entre España y Portugal. Esta amplia población foránea, móvil y no afincada de manera estable en la ciudad-puerto, conducía a acentuar en Buenos Aires lo que parece haber sido un rasgo estructural de las sociedades hispanoamericanas coloniales: un anonimato mayor que el que era viable lograr en la península ibérica de su tiempo. ${ }^{32}$ Así, la vulnerabilidad de las identidades personales se adosaba a la transgresión constitutiva de los tratos, exasperando la asimetría de la información y espoleando con ello los riesgos de oportunismo y selección adversa.

\section{5-1644: TIEMPO DE CAMBIOS EN UN CONTEXTO ARRIESGADO}

En diciembre de 1640 ocurre el levantamiento luso contra la corona castellana, provocando la ruptura de la unidad que ambos reinados sostenían desde $1580 .{ }^{33}$ La proclamación del duque Joâo IV de Bragança como rey de Portugal hizo que entre febrero y marzo de 1641 prácticamente todo Brasil se sumase al levantamiento bragancista. ${ }^{34} \mathrm{~A}$ estos acontecimientos

\footnotetext{
${ }^{31}$ González, Pequeña, 2002, pp. 154-155.

${ }^{32}$ Johnson y Lipsett-Rivera, Faces, 1998, p. 6.

33 Ceballos, "Arribadas", 2008, p. 253.

${ }^{34}$ Valladares, "Brasil", 1993, p. 155.
} 


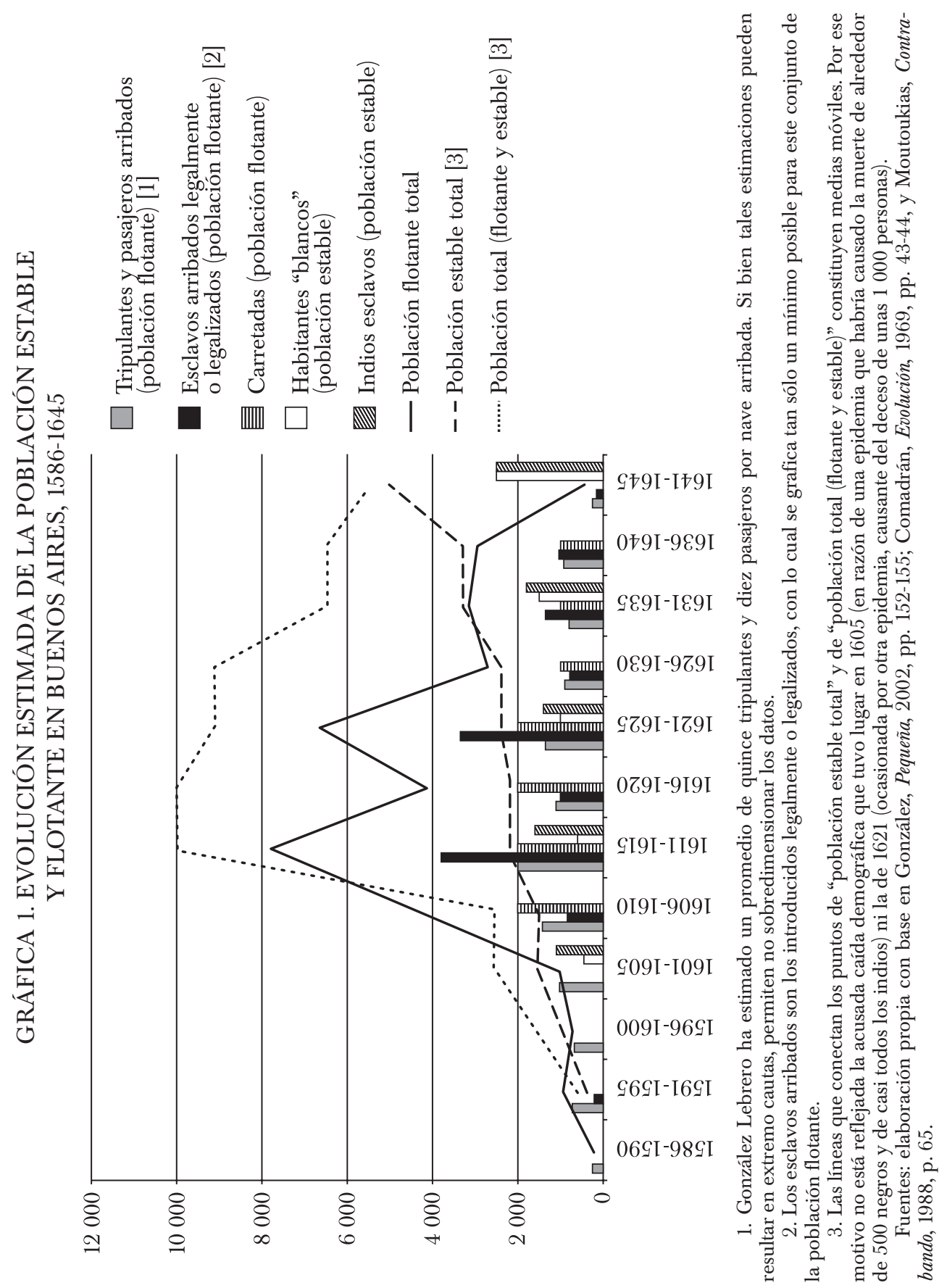


le seguiría el avance de los holandeses sobre Luanda en agosto de 1641, dejando al mercado de esclavos de Angola fuera del control castellano y portugués. Durante el primer semestre de 1641 la noticia de la secesión portuguesa llega a Buenos Aires, tal como lo muestran los acuerdos del Cabildo porteño. ${ }^{35}$ La conjunción de estos sucesos obstaculizó considerable, aunque no totalmente, el comercio porteño con la costa brasileña, dando lugar en Buenos Aires a un desmoronamiento del tráfico atlántico a partir de $1641 \mathrm{y}$ "obligando al sector mercantil a intentar el dominio de la producción rural". ${ }^{36}$ Desde entonces, las actividades de la ciudad-puerto parecen reorientarse hacia este sector, que adquiere primacía como actividad económica para la inserción de Buenos Aires en el espacio económico peruano. ${ }^{37} \mathrm{Es}$, como se ve, un momento de inflexión en el proceso de integración de Buenos Aires al espacio económico peruano y ello justifica su abordaje. En adelante serán las economías rurales y el comercio interregional los que pasen a protagonizar el mantenimiento de las personas, carretas y animales imprescindibles para la circulación, siendo desde entonces "el vaivén intercolonial el que mantenía la actividad comercial de Buenos Aires" ${ }^{38} \mathrm{Si}$ el movimiento portuario había comenzado a decaer desde la década de 1620, el quiebre de 1640 viene a dar comienzo a la finalización del periodo de primacía portuguesa en el abastecimiento atlántico a Buenos Aires, que a partir de la década de 1650 tendrá en los holandeses a uno de sus principales protagonistas, reactivándose de su mano el tráfico portuario. ${ }^{39}$ Esta coyuntura de implicancias nada despreciables parece haber concitado, sin embargo, escasa atención como momento de inflexión y como problema investigativo en los estudios sobre el temprano Río de la Plata, que tendieron a tomar esta coyuntura, tácita o explícitamente, como punto de finalización o de comienzo del periodo abordado.

${ }^{35}$ AGN, Acuerdos del extinguido Cabildo de Buenos Aires, libro IX, pp. 135 y 138-139. Luego, en 1643 el gobernador Gerónimo Luis de Cabrera intentará el desarme y expulsión de la población portuguesa residente y afincada en Buenos Aires, tentativa de destierro que explicitará una cristalización de lazos internos en la capa social dominante de Buenos Aires, complejizando para esta altura del siglo la simplificada imagen del binomio "beneméritos" versus "confederados". Véase Trujillo, "Facciones", 2009, pp. 341-358.

${ }^{36}$ González, Pequeña, 2002, p. 90. La historiografía sobre el tema es amplia y excede al marco porteño, pero podemos mencionar a Moutoukias, Contrabando, 1988, pp. 65-67, 207; Scheuss, Trata, 1958, p. 71; Saguier, "Economic", 1987, p. 124, y Fradkin y Garavaglia, Argentina, 2009, pp. 60-61.

${ }^{37}$ Moutoukias, Contrabando, 1988, p. 56.

${ }^{38}$ Ibid., p. 68.

${ }^{39}$ Cuando a comienzos de la década de 1650 el tráfico ultramarino consolide su reactivación, el sector agropecuario sufrirá contratiempos que detendrán el impulso adquirido desde 1640: la epidemia de 1651 arrasará con buena parte de la fuerza de trabajo, constituida por indios encomendados y negros esclavos, muriendo dos tercios del servicio de los vecinos porteños en el lapso de tres años. La sequía de 1654, entre tanto, terminará promoviendo la fuga masiva del ganado. Véase Birocco, "Ganado", 2003. 


\section{Los movimientos del crédito notariado durante una década de cambios}

Hemos sistematizado para la década de 1635-1644 la totalidad de operaciones crediticias realizadas en Buenos Aires ante la única escribanía pública y de Cabildo de la ciudad, los protocolos notariales ubicados hoy en el Archivo General de la Nación, en Buenos Aires. La gráfica 2 muestra la correlación interanual entre el movimiento de las importaciones registradas y el pulso de las transacciones de crédito formalizado notarialmente durante la década en cuestión; correlación que se interrumpe en 1641 con la escisión portuguesa y, luego, con la toma de Luanda por los holandeses.

Como se observa en el cuadro 1, la heterogénea tipología contractual que compone este universo de transacciones crediticias está encabezada por un importante conjunto de obligaciones y deudas, seguido por escrituras de venta que conllevaban el endeudamiento por la totalidad o una parte del valor del bien o servicio vendido, escoltadas por escrituras de censos consignativos y por un número menor de otras tipologías contractuales (recibos, finiquitos, poderes en causa propia, fianzas y arriendos). Cada una de estas escrituras ha habilitado la creación de una deuda, configurando jurídicamente la correspondiente obligación de reintegro. ${ }^{40}$

Exceptuando a los censos consignativos, puede apreciarse que el resto de los instrumentos consistía en operaciones de corto plazo. A su vez, la formalización escriturada del reintegro distaba de ser absoluta en relación con el total del valor anticipado, tendencia que se agudizaba ante disrupciones en la regularidad del comercio portuario. ${ }^{41}$

${ }^{40}$ Gelman, "Economía”, 1987, ha sugerido qué porciones de metálico quedaban en la ciudadpuerto tanto por la vía fiscal (retenciones sobre impuestos comerciales para el sostenimiento del aparato administrativo y defensivo) como por la presencia de comerciantes potosinos, chilenos o tucumanos que realizaban desembolsos de plata en Buenos Aires. Grupos de grandes comerciantes porteños lograban con ello absorber moneda metálica, reintroduciéndola (conjuntamente con aquella burocracia, de la que podían formar parte) en la sociedad porteña, mediante créditos en moneda o en efectos, creando con ello redes de dependencias. Saguier, "Economic", 1987, ha detectado que en situaciones de paz y fluidez en el comercio ultramarino había escasez de metálico en la ciudad-puerto, estimulándose la venta a crédito e incrementándose el porcentaje de prestatarios sobre prestamistas. Sugiere que ante declaraciones de guerra de España, los mercaderes en Buenos Aires procuraban acaparar todos los productos europeos posibles para especular con el incremento de sus precios: pero las posibilidades de retener la mercadería volvían imprescindible el empleo de crédito. En este sentido, Saguier sugiere que la trata de esclavos pudo haber constituido la principal determinante de la expansión en la venta a crédito en Buenos Aires desde 1593 hasta 1640, conduciendo a ciclos de expansión y contracción del crédito, correlativos con los ciclos comerciales.

${ }^{41}$ Nos explica Sara Mata de López en su estudio sobre el crédito en Salta hacia fines del siglo XVIII que "abonada la deuda se inscribía en los márgenes de la obligación la fecha de cancelación", aunque en algunos casos "las cancelaciones se realizaban en otros lugares y no se procedía luego a inscribirlo en los protocolos, o esas cartas de deudas circulaban entre los comerciantes hasta su cancelación, sin que su caducidad constara en el instrumento público archivado en el Cabildo. De todas maneras, cuando los deudores eran vecinos comerciantes o estancieros de la 


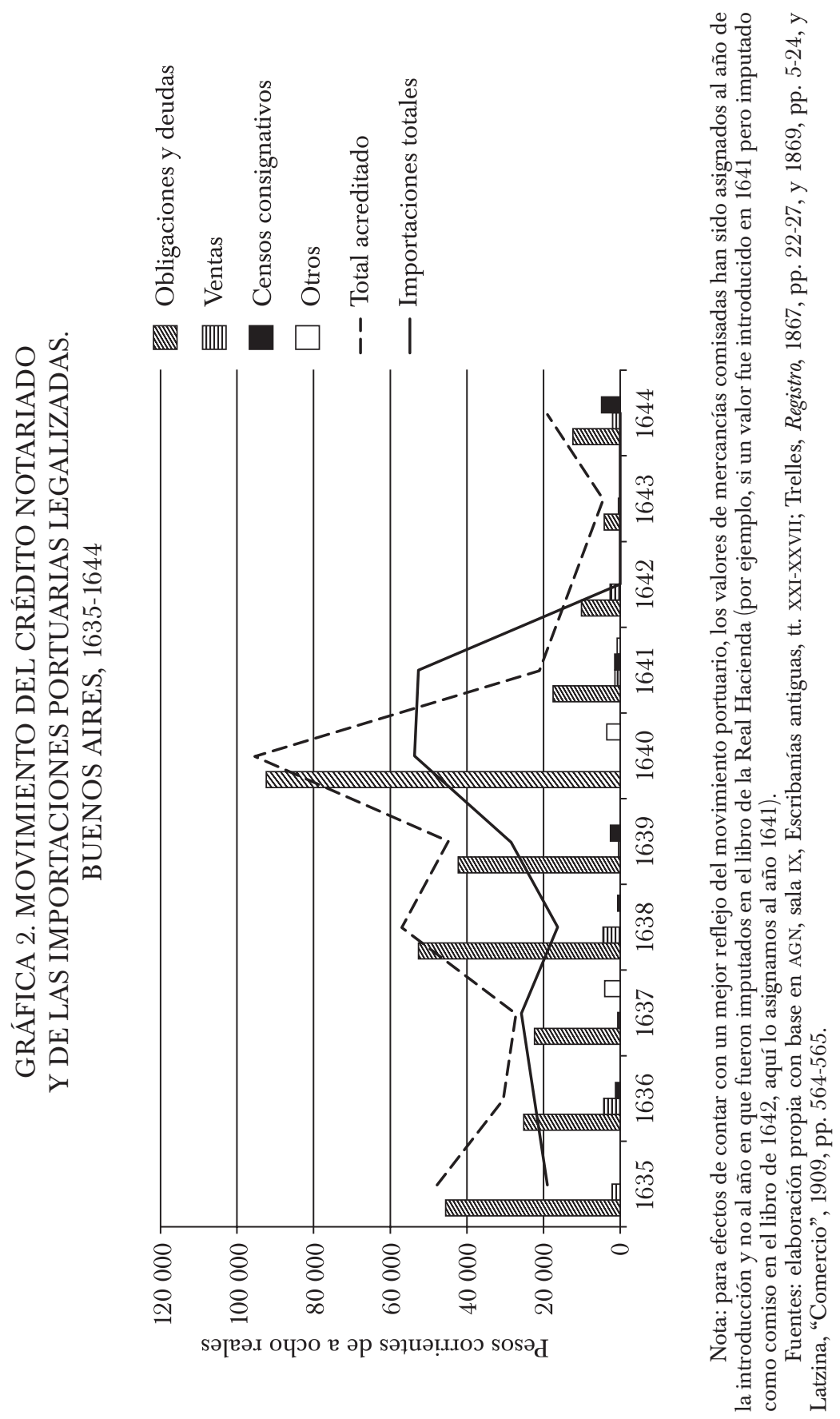




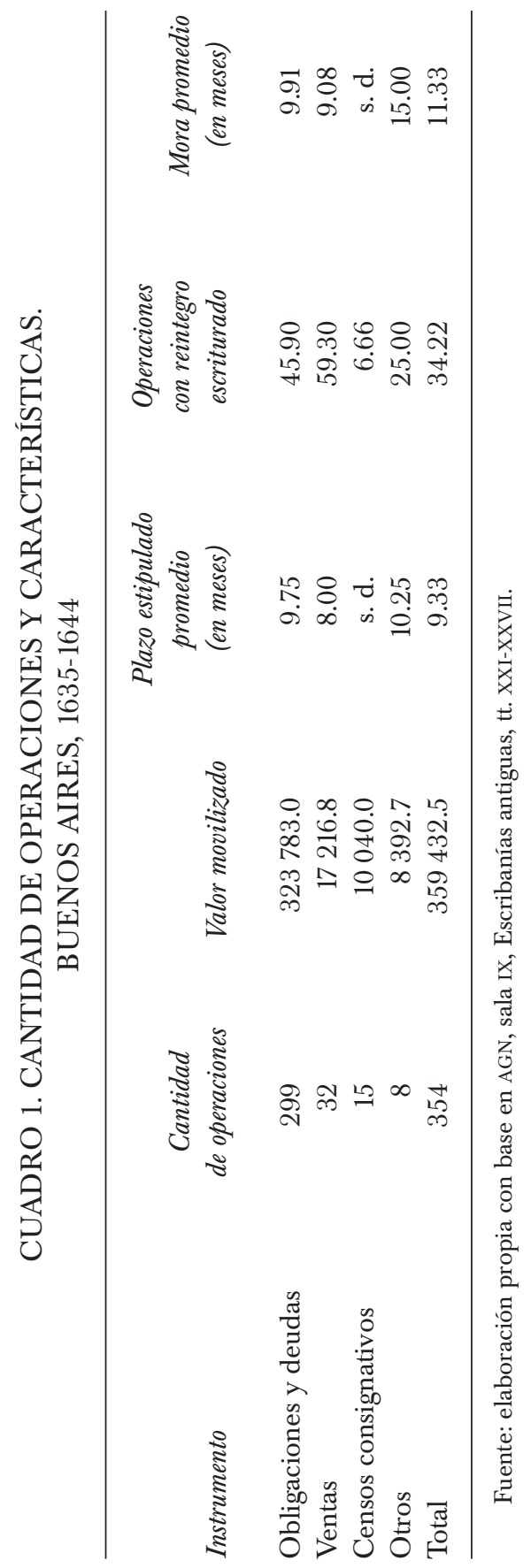


Las obligaciones de pago (obligaciones) y los reconocimientos de deuda (deudas) protagonizaron las transacciones registradas ante el escribano público durante el periodo, sin diferenciarse morfológica ni tipológicamente en el protocolo notarial; se nos presentan así como dos modos distintos de designar al mismo tipo documental según el arbitrio o la práctica de los sucesivos escribanos que oficiaron en la escribanía pública y de Cabildo porteña. ${ }^{42}$ Podían responder a la entrega de metálico ante el escribano (9.4\% de las escrituras de obligación y deuda), a la entrega con pago diferido de mercancías o de esclavos que contasen con sus correspondientes despachos provistos por los oficiales de la Real Hacienda (6\%), o podían responder formalmente al anticipo de metálico, pero cuya transferencia entre acreedor y deudor no comparecía ante el escribano y los testigos -como en el primer caso-, lo cual impedía al notario dar fe de la transferencia de la moneda $(84.6 \%)$. En otro trabajo se avanza sobre la hipótesis de que estas operaciones formalmente monetarias hayan encubierto la creación de deudas derivadas del anticipo de mercancías y esclavos de introducción y circulación ilegal, proveyendo así un instrumento legalmente ejecutable ante un contexto de elevado riesgo de pérdida del capital. ${ }^{43}$ $64 \%$ de las obligaciones o deudas que respondían a la entrega de moneda metálica (real o formalmente) no especificaba el destino económico que se daría al crédito obtenido; $23 \%$ se destinaría al avío, despachos y gastos de viaje; $8 \%$ sería destinado a saldar deudas y necesidades; $3 \%$ consistía en dinero adelantado a crédito para la adquisición de mercancías y medios productivos; el 2\% restante se aplicaría a destinos varios. El destino económico de las obligaciones y deudas que respondían a la entrega a crédito de mercancías o esclavos puede inferirse de la particularidad misma de los valores acreditados: si bien 50\% de estas obligaciones o deudas tampoco detallaba las mercancías, el otro $50 \%$ se distribuía entre obligaciones que

ciudad de Salta, existiese o no en las cartas de crédito la hipoteca de sus propiedades, la falta de pago de sus créditos concluyó con el remate de sus bienes para proceder a saldar sus deudas", Mata, "Crédito", 1996, p. 159. Hemos reconocido en los protocolos porteños, sin embargo, escrituras canceladas en otras plazas cuya notificación de cancelación era trasladada al registro de Buenos Aires. Véase AGN, sala IX, Escribanías antiguas, t. XXV, 48-4-2, fs. 149r-149v, 14 de octubre de 1639, donde se traslada al protocolo notarial porteño una cancelación que tuvo lugar en Jujuy; ibid., fs. 259r,-259v, 15 de diciembre de 1642, donde se traslada una cancelación que tuvo lugar en Córdoba; ibid., t. XXII, 48-3-7, fs. 411v-412r, 12 de septiembre de 1636, donde se incorpora a la deuda creada en Buenos Aires el traslado de su cancelación, que tuvo lugar en Potosí al año siguiente. Con lo cual, aun cuando es posible que la práctica de formalizar notarialmente la cancelación de las deudas escrituradas distase de reflejar la totalidad de deudas efectivamente canceladas, la proporción cambiante de cancelaciones incorporadas al protocolo constituye, sin embargo, un buen reflejo de la cambiante tendencia a cancelar las deudas a lo largo del periodo.

${ }^{42}$ En efecto, numerosas escrituras cuya morfología se adecua a las deudas u obligaciones carecen de intitulado, demostrándose que la designación podía alternarse pero también -o por ello mismo- podía obviarse.

${ }^{43}$ Wasserman, "Esclavos", 2011, pp. 817-831. 
respondían a la entrega de hacienda y ganado vacuno (dos escrituras), esclavos legalmente introducidos o legalizados (dos escrituras), la entrega a crédito de un inmueble urbano (una escritura), así como deudas derivadas de la entrega de yerba, vino, cáñamo y un aderezo de espada (una escritura en cada caso). Como puede apreciarse, durante esta década las deudas y obligaciones funcionaban como instrumentos de corto plazo destinados a articular los engranajes de la circulación, así como a compensar los apremios de endeudamientos previos y, muy subsidiariamente, a fortalecer la producción del área. En efecto, los plazos del grueso de estas escrituras están determinados por las dilaciones temporales del circuito interregional: Acarette du Biscay, quien pasó por Buenos Aires en 1658 y dejó testimonio sobre su travesía mercantil hacia Potosí, explicaba que los comerciantes potosinos recibían las noticias de las partidas arribadas al puerto bonaerense, "pero los efectos no llegaban a su poder hasta siete u ocho meses después". ${ }^{44}$

Las escrituras de venta también movilizaban la entrega de bienes sin la contrapartida inmediata del pago, por lo cual habilitaban asimismo la puesta en circulación mediante la creación de deudas. $44 \%$ de las escrituras implicaba la venta a crédito de inmuebles urbanos, otro $22 \%$ de escrituras implicaba la entrega de inmuebles rurales a crédito; $22 \%$ de los contratos de venta canalizó deudas emergentes de la entrega de ganado vacuno; 9\% de escrituras de venta permitió formalizar las deudas derivadas de la entrega de esclavos (exigüidad que contribuye a nuestra hipótesis sobre el empleo de obligaciones y deudas formalmente monetarias como instrumento para movilizar transacciones ilegales). La escritura restante (que hace 3\% de los contratos de venta con deuda en esta década) sirvió para transferir una propiedad urbana sobre la cual pesaba un censo destinado al sostenimiento de la capellanía de la virgen de Copacabana, fundada en la iglesia catedral de Buenos Aires. En este conjunto de operaciones (muy inferior en cantidad y capital que las obligaciones y deudas) volvemos a encontrar la primacía del patrimonio urbano y sus actividades comerciales como destino del crédito, por sobre el destino rural del mismo.

El censo consignativo presentaba las conocidas singularidades jurídicas que lo distinguían de otras operaciones crediticias: el censualista (acreedor) compraba al censuario (deudor) el derecho a la percepción de una renta anual (réditos) a cambio de la entrega de un capital (principal), de modo que jurídicamente no constituía un préstamo, sino una venta y, por ello, el pago de intereses (réditos anuales consistentes desde 1608 en $5 \%$ sobre el principal ${ }^{45}$ se concebía como la justa retribución por una

\footnotetext{
${ }^{44}$ Acarette, Relación, 1943, p. 38.

${ }^{45}$ Martínez, "Mecanismos", 1993, p. 48.
} 
venta (y no como el cobro de un porcentaje sobre la cantidad prestada). ${ }^{46}$ El censo era consignativo puesto que se imponía sobre un bien raíz propiedad del deudor, que quedaba entonces gravado por el censo. ${ }^{47} \mathrm{Y}$ en nuestro caso constituían censos consignativos "al quitar" o redimibles, de modo que el censo se extinguía cuando el deudor restituía el capital pero no se estipulaba plazo alguno para dicha cancelación ${ }^{48}$ (motivo por el cual no se estima un plazo promedio de reintegro estipulado). $60 \%$ de las escrituras de censo consignativo del periodo no explicitan el destino que se otorgaría al capital acreditado; $27 \%$ de los contratos explican que el principal sería destinado al reparo de las unidades productivas rurales y la adquisición de hacienda por parte del censuario; entre tanto, los réditos de otro censo serían destinados al sostenimiento de una capellanía, mientras que en la escritura restante no era metálico, sino un solar con casa el bien que fungía como principal. $60 \%$ de los censos era consignado sobre inmuebles urbanos; 27\% sobre inmuebles urbanos y rurales conjuntamente; el 13\% restante sobre inmuebles rurales solamente. Como en otras coordenadas de América Latina, también en Buenos Aires el censo se adaptaba más eficazmente a las necesidades financieras del espacio productivo rural, aunque el movimiento crediticio que este suscitase se viera muy relegado en comparación al movilizado por la actividad comercial.

Un estrecho conjunto de operaciones diversas contribuyeron a movilizar 2.33\% del valor acreditado, consistiendo en tipos documentales varios (recibos, finiquitos, poderes en causa propia, fianzas y arriendos) que creaban obligaciones apelando parcialmente a las estructuras documentales previamente mencionadas pero sin identificarse plenamente con ellas.

A lo largo de la década sólo han sido registradas dos compañías en el protocolo notarial porteño. El 5 de septiembre de 1637 emprenden una compañía Luis de Villegas y Juan de Borda, ambos avecindados en Buenos Aires, mediante la cual el primero, propietario de una tierra para estancia y chacras en el pago de Las Conchas, apela a Borda para que coordine el trabajo de "gente a serviçio a costa de ambas partes" con la cual recoger ganado "de las partes y lugares donde tubiere", aquerenciarlo en la

\footnotetext{
${ }^{46}$ Wobeser, "Mecanismos", 1989, p. 5. Como sugiere la autora, mediante esta "argucia legal" fue posible "obtener intereses por el capital invertido sin estar expuesto a la condena por usura". Si bien estamos en vías de preparar un trabajo sobre el censo como instrumento crediticio de largo plazo en Buenos Aires durante el siglo XVII, adelantamos que en algunos casos este mecanismo era instrumentado para fundar y sostener capellanías mediante réditos anuales derivados de la imposición a censo de un principal. En estos casos, las instituciones eclesiásticas solían no participar con capitales propios (aun habiendo primado como acreedoras censualistas durante todo el periodo) sino administrando el capital que terceros destinaban a censos y percibiendo los réditos resultantes.

${ }^{47}$ Martínez, "Mecanismos”, 1993, p. 47, y Génesis, 2001, p. 67.

${ }^{48}$ Martínez, Génesis, 2001, p. 63.
} 
estancia, herrarlo y construir un corral para tal efecto. ${ }^{49}$ Asimismo, el 2 de enero de 1642, Diego de Vega y Frías (alcalde ordinario) constituía una compañía con Gonzalo Álvarez mediante la cual el primero, propietario de una chacra en el pago de Monte Grande, la otorgaba en arriendo al segundo por el término de cuatro años, "para que durante el dicho tiempo pueda labrar cultivar e beneficiar las tierras tocantes e pertenescientes a la dicha chacara".$^{50}$ Puesto que en el presente trabajo focalizamos el análisis sobre aquellas escrituras mediante las cuales las partes configuraban jurídicamente la creación de una deuda y su correspondiente obligación de reintegro, relegamos para otra ocasión el estudio sobre el instrumento de las compañías como mecanismo de financiación, cuya exigüidad nos permite, sin embargo, dar cuenta de su existencia. ${ }^{51}$

La relevancia de los valores puestos en circulación a través de los instrumentos crediticios ofrecidos por el cauce notarial es evidente, entonces, cuando la cotejamos con los valores importados que han sido registrados por los oficiales locales de la Real Hacienda (ya sea porque hubiesen sido introducidos legalmente o porque su comiso condujese al registro) (véase gráfica 2).

\section{La participación de los actores}

$\mathrm{Al}$ tomar en cuenta la frecuencia de intervención de los actores en relación con el conjunto de operaciones concretadas, observamos el panorama ofrecido en el cuadro 2 .

${ }^{49}$ AGN, sala IX, Escribanías antiguas, t. XXIII, 48-3-8, fs. 446r-449v.

${ }^{50}$ Especulaban con levantar en la chacra un "obraje de texa", cuyos beneficios se habrían "de partir entre los dos, restados antes todas cosas los gastos y costas y salarios". El carbón y la madera que durante la vigencia de la compañía se pusiere en el Río de las Conchas "yo, el dicho General Diego de Vega e Frias, lo tengo de acarrear con mis carretas bueyes y gente desta ciudad a mi costa". El capital aportado por el socio capitalista consistía en los medios productivos necesarios para el despliegue de la empresa rural. Sin embargo, la compañía parece no haber conducido a buen puerto: a tan sólo siete meses, el 12 de septiembre de 1642, ambos socios, de común acuerdo y conformidad, "deshazen y dan por ninguna esta compañía". Ibid., t. XXVI, 48-4-3, fs. 433r-435v.

${ }^{51}$ Asimismo, relegamos en este artículo un análisis sobre los juros, toda vez que este mecanismo involucraba la participación protagónica de la Real Hacienda como parte contractual, con una lógica institucional diferenciada de los actores que mayormente tomaron parte en las transacciones que observamos. Los juros constituyeron un recurso fiscal transitorio destinado a incrementar los ingresos del tesoro real, consistente en la emisión de títulos que ofrecían rentas anuales respaldadas en la recaudación fiscal. Lanzado en 1608, 1639, 1640 y 1641 para afrontar los gastos derivados de la guerra con otras potencias europeas, el mecanismo de la venta de juros desplegaba un engranaje de intereses en el ámbito local, por cuanto las Cajas Reales aseguraban con sus ingresos el pago de réditos anuales en concepto de $5 \%$ de interés (en tres partidas -abril, agosto y diciembre-) a sus acreedores. Para la zona peruana analizada por Kenneth Andrien, entre los acreedores de juros resaltaban monasterios y conventos, aunque también mineros, mercaderes y terratenientes. Véase Andrien, "Sale", 1981. 


\section{CUADRO 2. PARTICIPACIÓN DE LOS ACTORES Y FRECUENCIA DE INTERVENCIÓN}

\begin{tabular}{lccc}
\hline Instrumento & $\begin{array}{c}\text { Relación } \\
\text { deudores/acreedores }\end{array}$ & $\begin{array}{c}\text { Intervienen entre una y tres veces } \\
\text { Acreedores }\end{array}$ & $\begin{array}{c}\text { Deudores } \\
\text { Obligación de pago y }\end{array}$ \\
$\quad$ & & \\
$\quad$ reconocimiento de deuda & 1.55 & 44 & 69 \\
Venta & 1.00 & 89 & 100 \\
Censo consignativo & 2.16 & 70 & 100 \\
Otros & 1.28 & 100 & 100 \\
\hline
\end{tabular}

Fuente: elaboración propia con base en AGN, sala IX, Escribanías antiguas, tt. XXI-XXVII.

Es notoria la preminencia, en el universo del crédito protocolizado durante la década, de una baja frecuencia de intervención por parte de los actores. En el conjunto de operaciones (ya no desagregadas según la naturaleza del instrumento) priman aquellos acreedores que intervienen una sola vez como tales, comprendiendo $66 \%$ del total de las operaciones; posteriormente, aquellos que acreditan dos y tres veces comprenden otro $20 \%$. De manera que casi $90 \%$ de los acreedores interviene entre una y tres veces como tales a lo largo de esta década, prevaleciendo entre ellos los que sólo una vez lanzan valores por este cauce. Atendiendo a los deudores, se revela una situación similar: $65.3 \%$ de los tomadores intervienen como tales sólo una vez, mientras que $25.4 \%$ lo hace entre dos y tres veces. De manera que más de $90 \%$ de los deudores intervienen entre una y tres veces, prevaleciendo asimismo entre ellos quienes lo hacen sólo una vez a lo largo de la década. En efecto, la relación de deudores por acreedor en cada instrumento (véase cuadro 2) conduce a un patrón de elevada dispersión o baja concentración de operaciones en pocos agentes (si bien, algunos individuos, como veremos más adelante, sobresalieron en calidad de acreedores sin por ello romper el patrón mencionado de baja frecuencia y elevada dispersión, características de las prácticas crediticias notariadas para esta década).

\section{LA RED CONTRACTUAL: ¿EXPLICACIÓN O EXPRESIÓN?}

Queda evidenciada la preeminencia de actores que sólo una vez participan como acreedores y/o como tomadores de valores a crédito mediante el canal formal de la escribanía. De modo que si bien en algunos casos un 
mismo actor pudo intervenir en más de una ocasión, solía hacerlo bajo papeles diferenciados (como deudores en unas ocasiones y como acreedores en otras). Se evidencia asimismo que quienes mayor cantidad de operaciones acreditan, sólo en pocas ocasiones vuelven a cruzarse con el mismo tomador: Juan de Tapia de Vargas, el principal acreedor, distribuye sus transacciones en 0.93 deudores por operación, siendo que sólo a dos de sus deudores les anticipa valores en dos ocasiones (acreditando sólo una vez al resto de sus tomadores a lo largo de la década); lo escoltan, por un lado, el capitán Pedro de Roxas y Azevedo, quien incrementa sus riesgos al contar con un deudor por operación (siendo que ningún tomador contrata con él más de una vez a lo largo de la década) y, por otro lado, el clérigo Martín Martínez de Eulate, acreedor con la mitad de operaciones que Tapia, quien cuenta con 0.8 deudores por operación (puesto que dos de sus quince tomadores otorgan cinco escrituras). Remitiéndonos al otro extremo de la nómina de acreedores, todos aquellos que anticiparon por la vía del notario en sólo dos ocasiones lo hicieron a dos deudores diferentes (y no debemos perder de vista que, más allá de esto, prevalecen en el conjunto de acreedores quienes sólo una vez participan como tales en el despacho notarial porteño). Entre tanto, los deudores que mayor cantidad de operaciones tienen otorgadas ante el escribano no por ello son quienes más frecuentemente han acudido a un mismo acreedor: es así como al tendero Juan de Tejeda, el deudor más frecuente, sólo dos acreedores le anticipan valores en más de una ocasión (puntualmente, dos operaciones cada uno); entre tanto, al genovés Horacio Cota -tomador que lo sigue en el orden de frecuencia- un solo acreedor le anticipa valores en dos ocasiones. Si bajamos la vista hacia los deudores que han intervenido en dos ocasiones, observamos que sólo tres de ellos realizan ambas operaciones con un mismo acreedor. ${ }^{52}$ Todo ello conduce a que, en términos generales,

${ }^{52}$ Philip T. Hoffman, Gilles Postel-Vinay y Jean-Laurent Rosenthal han estudiado la frecuencia de interacción entre acreedores y deudores para el crédito notariado en la París del antiguo régimen. Tomando como muestra el año de 1751, los autores reconocen un patrón similar al que encontramos en Buenos Aires a lo largo de una década del siglo XVII: "borrowers showed no tendency to return repeatedly to the same lender or small number of lenders, as they would if they were earning lenders' trust or their own. Each new loan meant a new partner. Nor did lenders restrict their dealings to the same small set of trustworthy borrowers. Lending was simply not confined to small groups based on trust: borrowers and lenders alike were constantly reaching out to new partners." Hoffman, Postel-Vinay y Rosenthal, "Information”, 1999, p. 84. En este sentido, los autores explican que "renewing loans and increasing their size, lenders might come to trust borrowers; they would tend to limit their lending to those who, via such repeated dealings, had earned their trust. If so, we would expect borrowers to return over and over again to the same lenders. A borrower might seek a large number of loans but would deal repeatedly with the same lender, or perhaps the same small group of lenders. Alternatively, lenders might limit their dealings to borrowers whose assets and reputation inspired financial confidence [...]. In that case, there might be many lenders, but they would return repeatedly to the same borrower or small 
presenciemos que la densidad de la trama crediticia notariada sea considerablemente baja para esta década: $0.00363 .^{53}$

La morfología del conjunto de lazos instituidos contractualmente permite reconocer que el escribano público y de Cabildo porteño puso en contacto a sujetos dispuestos a lanzar a la circulación sus valores y a personajes dispuestos a tomarlos, aun ante la posible inexistencia de lazos interpersonales entre ambos. La constante y fluctuada presencia de una población flotante conducía al necesario encuentro de personajes afincados y públicamente reconocidos con sujetos de procedencia y reputación no siempre conocidas y, asimismo, daba lugar a tratos entre estos últimos. Esto conducía, habitualmente, a prescindir del crédito social de la persona como condición para el acceso al crédito económico. En otras palabras: a operar por fuera de los círculos de relaciones sociales confiables. La mediación notarial pudo ofrecer un soporte adecuado para desplegar los contactos ante un contexto signado por un riesgo alto aunque ineludible y una confianza necesaria aunque mínima.

Como hemos anticipado, la escribanía pública y de Cabildo de la ciudad de Trinidad y puerto de Buenos Aires de ese periodo era el único cauce notarial por el cual pasaban las transacciones que precisaban de escrituración legal en la ciudad, a diferencia de la multiplicidad de registros y escribanías que coexistían y competían por clientela en otras ciudades de América Latina y de Europa del antiguo régimen. ${ }^{54}$

group of borrowers. In any event, lending would remain confined to sets of partners who had gained one another's trust whether through previous dealings of financial reputation." Ibid., p. 82.

${ }^{53}$ Calculada como $l / n(n-1)$, siendo $l$ el número real de lazos y $n$ el número de actores involucrados en una estructura direccionada y, consecuentemente, asimétrica. Conviene recordar que las tramas con densidad valuada en 1 son aquellas en las que la totalidad de participantes está interconectada: como puede apreciarse hay una distancia considerable respecto de ese valor en el universo relacional del crédito notariado porteño para la década abordada.

${ }^{54}$ En Quito los escribanos "se mostraron reacios a introducir ciertas regulaciones dictadas por las autoridades, argumentando que, si las aplicaran, se ganarían la hostilidad de sus propios clientes. Esto ocurrió incluso cuando las regulaciones podrían haber supuesto en realidad una mejora en sus propios ingresos. [...] De la misma manera, los escribanos quiteños evitaban -siempre que podían- apremiar a las partes o a sus representantes, aun cuando esta era su obligación [...]. Ellos explicaban que una actuación así de su parte les hubiera ganado mala reputación entre sus clientes y en la sociedad en general, situación que deseaban evitar a toda costa." Herzog, Mediación, 1996, p. 105. Es que en lugares como Quito existía un verdadero mercado "en el cual cada escribano intentaba parecer mejor y atraer más público [...]. La capacidad de hacerse elegir para llevar muchos y buenos negocios era la que garantizaba las rentas del oficio y, en consecuencia, generaba la fama del escribano, lo que, a su vez, podía influir para obtener más clientes y mejores ingresos", en ibid., pp. 106-107. En París, durante los siglos XVII y XVIII "if a notary mistreated a client (by arranging a loan slowly, for instance, or by pairing a lender with an insolvent borrower), the client could switch rather easily to another notary, at least in most cases. [...] The threat of losing trade -and not any policing by the state or the corporation of notaries themselves- kept most eighteenth-century notaries competitive and prevented them from abusing their clients". Hoffman, Postel-Vinay y Rosenthal, "Information”, 1999, pp. 80-81. 
Pablo Núñez Victoria, Alonso Agreda de Vergara y Sebastián González Ruano se sucedieron como escribanos en este único registro que Buenos Aires poseía entonces. Constituyendo el único registro de la ciudad y careciendo de la competencia para atraer clientela que existía en otros puntos de América y de Europa del antiguo régimen, los réditos de este oficio no parecen haber vuelto a la escribanía una ocupación predilecta en la ciudad: la pesada labor conducía a continuos pedidos de licencia para realizar tareas menos pesadas y más redituables. Núñez Victoria explicaba en 1640 que don Juan de Palacios lo había convocado como escribano para proseguir la visita de la Audiencia de Charcas (y pedía un suplente interino), ${ }^{55}$ mientras que en 1642 González Ruano pedía licencia para "yr a mi casa e usar mi officio de rregidor" ${ }^{56}$ Por estas razones el protagonismo del periodo abordado recayó sobre Agreda de Vergara, hermano del poderoso vecino confederado Juan de Vergara, quien aparte de ejercer el oficio por su nombramiento, ocupó las suplencias mencionadas, demostrándose con ello que era su posicionamiento en la ciudad lo que reducía para él los costos de oportunidad de ejercer el oficio notarial. Fueron sus plumas, en suma, las que configuraron contratos, acopiando documentos en archivos proveedores de información y enlazando sujetos que precisaban de aquellas escrituras con las cuales homologar legalmente sus negocios. Invisibilizadas en la telaraña contractual, eran sus manos las que anudaban esta red.

¿Constituyeron estos vínculos contractuales una articulación compleja de los lazos primarios? ¿Derivaban del nivel más íntimo de relaciones interpersonales? ¿Estaban sostenidos en el parentesco? La descentralización de estos vínculos y su consecuente dispersión, la baja frecuencia mencionada en la intervención de los actores y la escasa reincidencia de contactos entre mismos agentes constituyen atributos de estas prácticas notariadas de crédito y las muestran como un cúmulo de lazos originados por fuera $\mathrm{o}$ en los márgenes de los círculos más próximos de sociabilidad de los actores. Contactos que podían ser exteriores a los vínculos preestablecidos, o que podían sostenerse por confianzas debilitadas o lealtades receladas y, por ello, en los límites de las tramas constituidas. Los casos de los dos principales acreedores nos lo evidenciarán.

\footnotetext{
${ }_{55}$ AGN, Acuerdos del extinguido Cabildo de Buenos Aires, t. IX, libro V, pp. 84 y ss.

${ }^{56}$ Ibid., libro VI, pp. 293 y ss.
} 


\section{TAPIA DE VARGaS y RoXas y AZEVEDO: DOS GRANDES ACREEDORES}

El granadino Juan de Tapia de Vargas y el canario Pedro de Roxas y Azevedo, afincados en Buenos Aires, arrojaban una participación de acuerdo con los cuadros 3 y 4 en la década que venimos evaluando.

Tomando como parámetro el caso de Juan de la Cueva, gran mercader y banquero asentado en Lima de nuestro periodo, observamos claras diferencias de escala, pues movilizó al menos 9500000 pesos en 20 años. Considerando las obligaciones formalizadas notarialmente por este personaje, observamos que entre 1615 y 1635 fueron escrituradas a su favor unas 1018 transacciones ante el escribano en Lima. Sumando los préstamos al Estado y créditos a los mineros de Huancavelica, la suma acreditada ascendía a 2082444 pesos. ${ }^{57} \mathrm{Al}$ analizar a Tapia y a Roxas observamos a los protagonistas de una economía considerablemente más chica que la de Lima pero, a su vez, estructurada institucionalmente en función de una marginalidad legal que no pesaba sobre el diseño institucional limeño. No por marginal la economía porteña distaba de ser dinámica. Pero sus protagonistas debían ajustar esa dinámica y sus mecanismos de funcionamiento a las restricciones institucionales que pesaban sobre la ciudad rioplatense.

Para reconstruir la participación de sendos actores en el crédito notariado de Buenos Aires debemos retrotraernos hasta 1613, año de la llegada de Tapia a la comarca porteña, toda vez que no hemos relevado operaciones de Roxas antes de ese año. Los protocolos notariales se extienden así a 12963 folios, cuyo relevamiento nos devuelve el panorama diacrónico que ofrecemos en la gráfica 3.

Comenzando por Tapia, su trayectoria en las transacciones crediticias porteñas muestra que las deudas contraídas por él ante el notario alcanzan un total de 17267 pesos, distribuidos en escasas nueve operaciones, mientras que los valores por él anticipados ascienden a 37646.3 pesos mediante 71 transacciones (entre las que se cuenta una operación en la cual otorga a crédito 300 cabezas de ganado vacuno que no están apreciadas en el contrato y, por ello, no expresadas monetariamente en la gráfica $3)$. Sus acreedores son siete personas, y sus deudores 63. Los cambios en la relación entre los valores tomados y concedidos marcan la pauta de la trayectoria económica de este actor en Buenos Aires; es notorio cómo los primeros años de su afincamiento en la ciudad sólo lo muestran endeudándose para, desde 1618, comenzar a intervenir con cierta regularidad en cuanto acreedor. Ese mismo año, Tapia obtiene su carta de vecindad

57 Suárez, Desafíos, 2001, pp. 79-121. Un muestreo de 91 transacciones formalizadas notarialmente en Potosí a favor de Juan de la Cueva para los mismos años de 1615-1635 arroja créditos por 270404 pesos. 







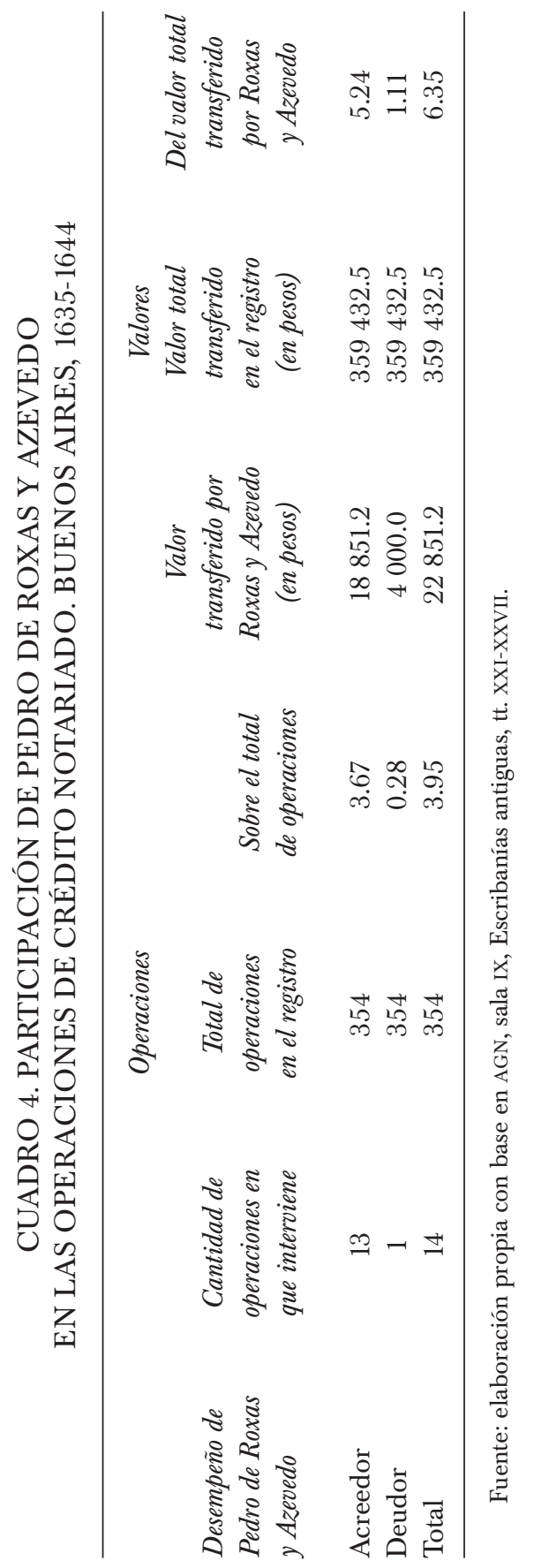




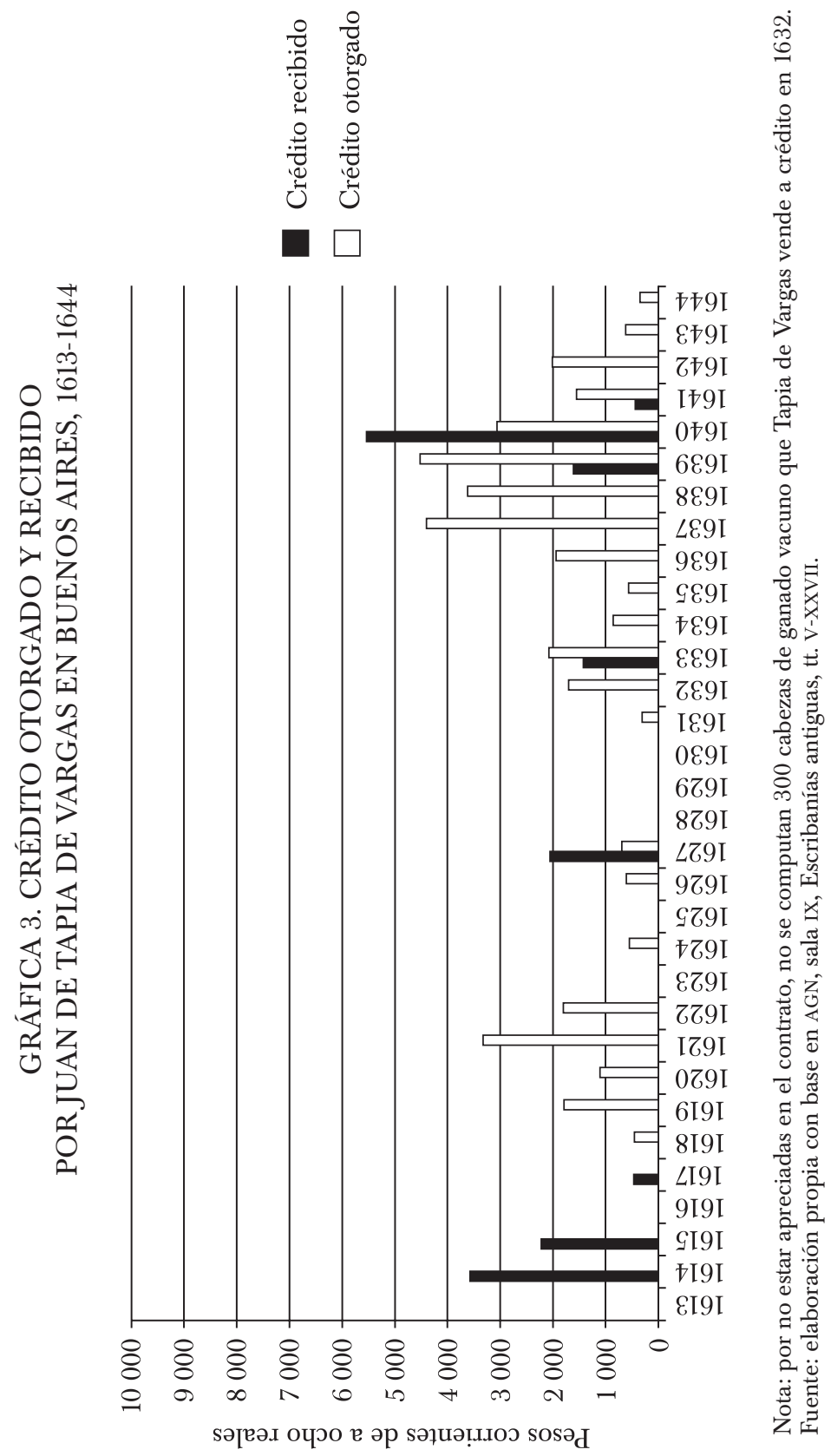


en la ciudad porteña. Este granadino había llegado a Buenos Aires sin compañía, pero las cuatro hijas legítimas de su primer matrimonio en Buenos Aires, con Leonor de Cervantes, le permitirán tramar lazos mediante dotes. Su segundo matrimonio, con Isabel de Frías Martel, también le proveerá recursos relacionales y patrimoniales. Varios cargos y oficios lo enaltecerán en la comarca, designado capitán de una de las dos compañías de caballos ligeros lanzas en 1619, alcalde de primer voto en 1624 y 1632, teniente de gobernador de Río de la Plata en 1631, alférez real entre 1631 y 1639, alguacil mayor del Santo Oficio entre 1630 y 1642 y contador para la Real Hacienda desde 1643. Al morir, en 1646, su inventario incluía quince inmuebles urbanos, doce unidades rurales, 8695 cabezas de ganado y 65 esclavos, junto a un enorme stock de mercancías textiles y de mercería, materiales para la construcción e insumos de ferretería. Supo contar, asimismo, con un obraje textil en el pago de la Matanza.

De las escrituras acreditadas por Tapia, 70\% constituía deudas (que movilizaron $80 \%$ del valor acreditado) y $29 \%$ obligaciones (que canalizaron $19 \%$ del capital), mientras que el 1\% restante constituía un finiquito (en el cual se incorporaba la creación de una obligación, movilizando $1 \%$ del capital acreditado por Tapia). 88\% de sus operaciones implicó la acreditación de moneda (aunque sólo en 9.4\% de estas la moneda metálica pasaba ante la mirada de los escribanos y los testigos); 11\% implicó la acreditación de bienes y esclavos, y la restante operación consistía en la sustitución de una deuda previa. $60 \%$ de sus operaciones no especificaba el destino económico que se daría a los valores acreditados, mientras que 19\% se destinaría al avío, 6\% consistía en la entrega de esclavos (aunque recordemos que estos podían anticiparse a crédito mediante obligaciones formalmente monetarias), 5\% para saldar deudas preexistentes del deudor y el resto de las operaciones tendría por objetivo la obtención de mercancías para conducir a Paraguay el pago por anticipado de 50 yeguas corraleras (concordante con la empresa de cría mular que aspiraba a desarrollar Tapia), la venta a crédito de cueros, frazadas, cabezas de ganado y mercancías varias sin detalle.

Conocemos diversos atributos socioeconómicos sobre 34 de los 63 deudores de Tapia, atributos que podían yuxtaponerse en algunas personas. Cinco de ellos tuvieron participación diversa en el Cabildo, tres en Gobernación y dos en la Real Hacienda. A su vez, 18 contaban con algún grado militar válido a la hora de formalizar las escrituras. Unas quince personas daban a conocer su especialización, entre ellos, cuatro mercaderes (que bien podrían identificarse como grandes comerciantes en esta ciudad todavía carente de un Consulado de Comercio que instituyese la identidad corporativa) y un tratante; dos vecinos encomenderos; dos plateros; un letrado en leyes; un dueño de navío; un médico y un barbero-cirujano; un mayordomo de estancia, y un sastre. Sólo uno de sus deudores estaba 
adscrito a la Iglesia. Y al menos ocho de sus deudores eran portugueses, con afincamiento variable en la ciudad. Una composición heterogénea.

Más de la mitad de los deudores de Tapia no radicaba en Buenos Aires de manera estable (55\% de las operaciones que contemplan $66 \%$ de los valores anticipados). Asimismo, la mayoría de sus tomadores (88.89\%) sostiene un único contacto crediticio con Tapia, corroborándose la baja frecuencia de contactos observada en la estructura general del crédito notariado. Inasibles por itinerantes y por distantes, el grueso de los deudores de Tapia parece constituir un mundo de vinculaciones tibiamente interpersonales, en donde el reconocimiento y la confianza, que podrían autorregular el vínculo en un ámbito de lazos informales, se diluyen en la escasa frecuencia de contactos para conducir, consecuentemente, a una necesaria mediación formal: la apelación a la institución notarial en cuanto mediadora informacional y al dispositivo contractual de obligación por esta provisto. Sin embargo, personajes que no eran tan distantes ni tan infrecuentes también conformaron, aunque en menor medida, el espectro de deudores de Tapia. Convendrá observar a continuación la estructura crediticia formal de Roxas para, entonces, poder aproximarnos a otros universos relacionales mantenidos por estos actores y evaluar qué relación sostuvieron estos con los lazos instituidos por el crédito formalizado (véase gráfica 4).

Las deudas contraídas ante el notario por Roxas ascienden a 4500 pesos distribuidos en sólo dos operaciones, mientras que anticipa valores por un total de 25012.2 pesos mediante 21 contratos (contemplándose uno en el cual Roxas anticipa 17 esclavos y cierta cantidad de hierro para su venta en el interior sin asignarles precio, por lo cual no se ha volcado su expresión monetaria en la gráfica 4). Esta participación, más esparcida en el tiempo y con menor regularidad que la de Tapia, expresa otro modo de inserción e integración en la sociedad y en la economía local. Como veremos, pudo tratarse de diferentes maneras de construir un crédito social necesario mediante distintas participaciones en el crédito económico. Es visible, entre tanto, que en 1626 comienza a participar con regularidad y ello puede expresar la solidificación de su persona en el papel que hasta hacía poco había desempeñado su hermano Gaspar, recientemente fallecido. Oriundo de Garachico, en las islas Canarias, Roxas contaba en Buenos Aires con su hermano Gaspar de Azevedo, un escribano de registros y Real Hacienda sólidamente inscrito en la red de comercio clandestino conocida como confederados. Con este importante anclaje local, en 1619 Roxas es designado solicitador del Real Fisco por el canciller de la Real Audiencia de la Plata y adquiere en 1621 el oficio de escribano público y de Cabildo de Buenos Aires, de bienes de difuntos y de la santa hermandad, que ejerce durante cuatro años. En 1626 será alcalde de segundo voto 


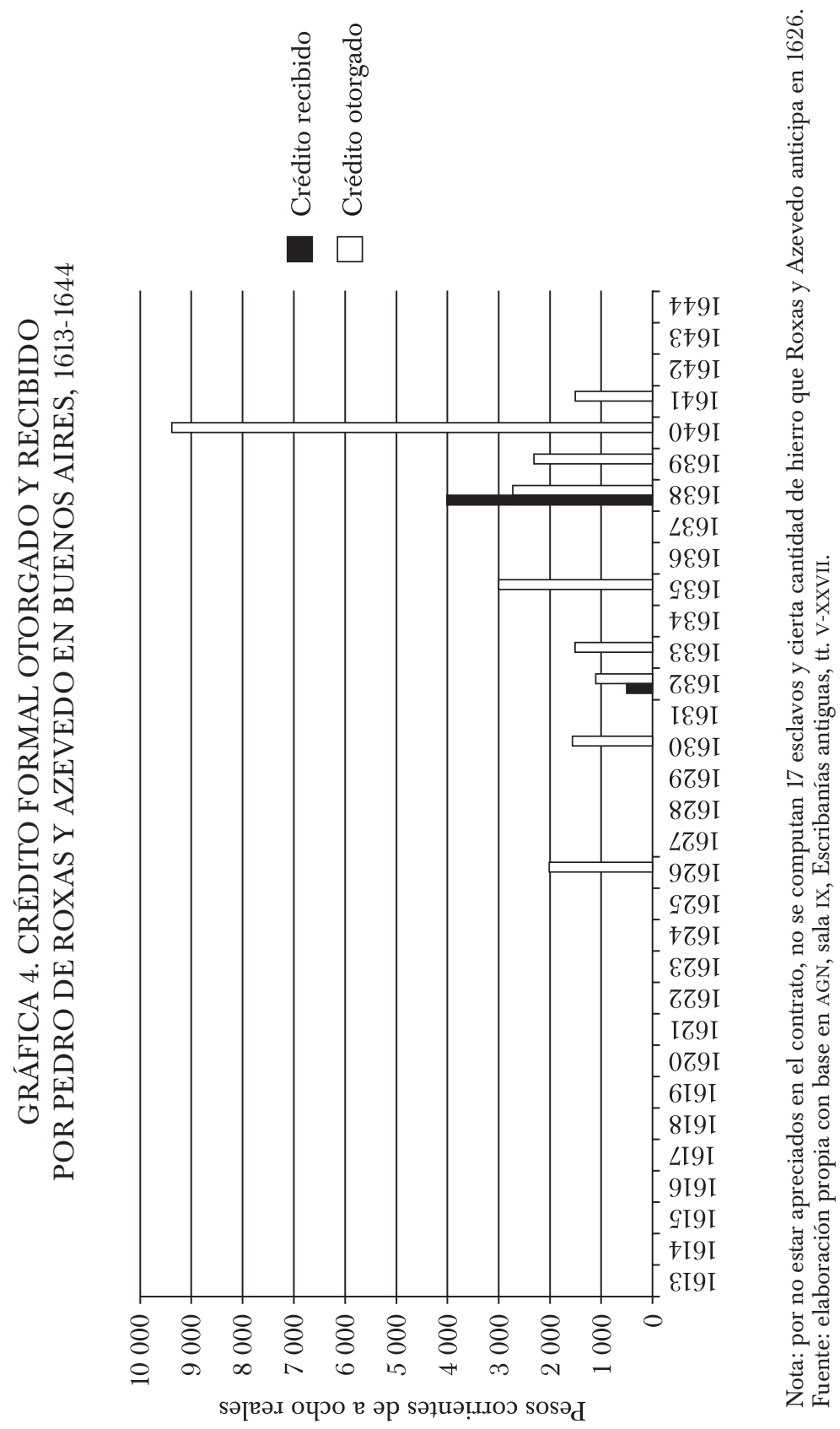


y en 1640 será teniente general de gobernador, reconocido como gobernador por el Cabildo en enero de 1641. Su matrimonio con María de Vega, hija del importante contrabandista portugués Diego de Vega (socio de su hermano Gaspar), solidificaba en 1622 su propia inscripción a las redes locales. Al fallecer, en 1642, su inventario incluía nueve inmuebles urbanos, dos unidades rurales, 4183 cabezas de ganado y 23 esclavos.

$57 \%$ de las escrituras acreditadas por Roxas consistió en deudas (que movilizaron $40 \%$ del valor acreditado) y $21 \%$ en obligaciones (que canalizaron $43 \%$ del capital), $11 \%$ consistía en escrituras de venta (3\% del valor acreditado por Roxas), $7 \%$ en censos (13\% del capital) y $4 \%$ lo conformaba un recibo (1\%). 61\% de sus operaciones implicó la acreditación de moneda (aunque sólo en 12\% de estas operaciones la moneda pasó ante la mirada del notario), 28\% consistió en la acreditación de bienes y esclavos, mientras que el 11\% restante consistía en la sustitución de deudas previas. $64 \%$ de sus operaciones no especificaba el destino económico que se daría a los valores acreditados, mientras que 11\% se destinaría a saldar deudas preexistentes del deudor; otro $11 \%$ consistía en la entrega a crédito de inmuebles (7\% propiedades urbanas, $4 \%$ propiedades rurales); $7 \%$ consistía en la entrega de esclavos a crédito (volvamos a recordar que estos podían anticiparse a crédito mediante obligaciones formalmente monetarias); el restante 3\% del crédito otorgado por Roxas se destinaría al avío.

Conocemos algunos atributos socioeconómicos sobre once de los 21 deudores de Roxas: tres de ellos tuvieron participación diversa en el Cabildo, uno en Gobernación y uno en la Real Hacienda. Entre tanto, cuatro contaban con algún grado militar. A su vez, conocemos la especialización de cinco de sus deudores: tres mercaderes; un carpintero y comerciante y un constructor. Nuevamente, sólo uno de sus deudores pertenecía a la Iglesia. Asimismo, por lo menos cuatro de sus deudores eran portugueses.

Entre tanto, más de la mitad de los deudores de Roxas radicaba en Buenos Aires de un modo estable (61\% de las operaciones, que contemplan $62 \%$ de los valores anticipados). En este caso, la totalidad de sus deudores establece un único vínculo de obligación notariado, volviéndose a corroborar la baja frecuencia de contactos observada en la estructura general del crédito notariado. Volvemos a encontrar la necesidad de una mediación formal ante un ámbito de sociabilidad que, evidentemente, no permite a las partes regular su vínculo desde pautas extralegales, como la confianza y el mutuo reconocimiento interpersonal. Sin embargo, es preciso remarcar una de las distinciones con Tapia, la cartera de deudores de Roxas es $66 \%$ más chica que la de aquel cuando consideramos la cantidad de personajes con los que adquiere contactos por esta vía, pero sólo 35\% más chica en cuanto a los valores anticipados por el cauce notarial. Dicho 
en otros términos, Roxas puede arriesgar más valor por contrato aun cuando precisa apelar con menor frecuencia a la mediación formal.

¿Qué puede aportar una mirada sobre la trama relacional que tanto Tapia de Vargas como Roxas y Azevedo sostuvieron y construyeron en el parentesco ritual?

Analizando los documentos parroquiales, 56 son los personajes con los que Tapia sostuvo lazos interpersonales en el ámbito de la ritualidad católica y sobre los cuales quedaron registros hasta nuestros días. A ellos habrá que agregar los 17 ahijados que mediaron y movilizaron buena parte de esas relaciones. Con ello se conforma un universo de 73 personas con las que Tapia articula vínculos tanto de un modo activo (apadrinando) como de un modo pasivo (siendo apadrinado). Participa, asimismo, en vínculos indirectos con personajes con los cuales sólo comparte, con mayor o menor frecuencia, instancias ceremoniales de terceros. Excluyendo a sus ahijados, evidenciamos que Tapia se desempeña en términos activos como compadre de 29 personas que lo solicitan como padrino de sus hijos e hijas; testigo en dos casamientos y padrino de bodas en otros dos matrimonios (y entre ambas participaciones sostiene lazos con cuatro personas en total). De modo que Tapia sostiene lazos activos, mediante bautismos y casamientos, con 33 personas de la ciudad.

Por contraste, son 96 las personas con las que Roxas aparece vinculado, directa o indirectamente, en los archivos parroquiales porteños. A estas habrá que agregar 23 ahijados que mediaron buena parte de esas relaciones. Con ello se conforma un universo de 119 personas con las que Roxas articula lazos de diversa índole, tanto de un modo activo como de un modo pasivo. Participa, asimismo, de lazos indirectos con personajes con los cuales sólo comparte ceremonias de terceros. Excluyendo a sus ahijados, Roxas participa en términos activos como compadre de 43 personas que lo solicitan como padrino de sus hijos e hijas; testigo en doce casamientos y padrino de bodas en un matrimonio (conllevando la vinculación activa con 26 personas). Siendo que apadrina a los hijos de uno de los matrimonios para el cual fue testigo y a los hijos de aquel para el cual fue padrino de bodas, resulta que Roxas ha sostenido lazos activos, mediante bautismos y casamientos, con 65 personas de la ciudad. Vemos así que este universo relacional es $97 \%$ más extenso que el detentado por Tapia, duplicando prácticamente la extensión de lazos activos de parentesco espiritual construida por este (véase gráfica 5).

Las mallas interpersonales representadas en el compadrazgo nos permiten rastrear los círculos o entornos de sociabilidad más próximos de Tapia y de Roxas, ofreciéndonos indicios fehacientes del segmento relacional más confiable de sus respectivos patrimonios, fungiendo como índices del capital social de estos acreedores y permitiéndonos observar la "construc- 


ción de los vínculos próximos, o la planificación de la confianza" por parte de cada uno de ellos. ${ }^{58} \mathrm{El}$ recorrido por los protocolos notariales y por los acuerdos del extinguido Cabildo de Buenos Aires nos mostró, asimismo, la presencia de personajes que sin verse adscritos a esos círculos íntimos de familiares y parientes, detentaban lazos secundarios con estos actores (participación en negocios comunes, contactos esporádicos de diversa naturaleza). A los efectos de continuar discerniendo qué función sostuvo el contrato notariado en un contexto social de negocios organizados reticular e interpersonalmente, corresponde abordar las intersecciones que existieron entre el universo relacional que hacía al círculo primario de sociabilidad y el universo de lazos construido por el crédito formal.

$\mathrm{Al}$ observar el nivel relacional en el que se ubicaron sus deudores notarialmente formalizados, hemos encontrado una composición similar en ambas carteras (véase cuadro 5).

Ambos instituyeron la menor proporción de sus vínculos legales de obligación crediticia con sujetos pertenecientes al nivel primario de lazos interpersonales, mientras los sujetos emparentados ritualmente conformaban $8 \%$ de los deudores con deudas escrituradas a favor de Tapia, constituían asimismo 9\% de los deudores de Roxas. Una proporción algo mayor del crédito formalizado legalmente fue otorgada a sujetos allegados, vinculados mediante lazos de diversa intensidad y calidad, que ocupaban un segundo nivel relacional en la medida en que no eran partícipes directos de aquel círculo de lazos primarios: encontrábamos de este modo que constituían 29\% de los deudores formales de Tapia y 24\% de los tomadores de Roxas. Finalmente, el grueso de los vínculos de crédito formalizados ante el notario tenía por deudores a personajes sobre los cuales no han quedado registros de otros lazos con estos acreedores; es así como 63\% de los deudores de Tapia y $67 \%$ de los de Roxas, se componían de sujetos con los que sólo se ha mantenido ese único contacto, movilizado por el crédito escriturado (véase gráfica 6 ).

Esta homogeneidad en cuanto a la ubicación relacional de los deudores con escritura demuestra que el contrato notariado de crédito tendía a instrumentarse en relación inversa al grado de proximidad entre los actores y al nivel de confianza en él implicado. Recordemos que ciertos mecanismos estructurantes de lazos interpersonales, como el parentesco ritual configurado mediante el compadrazgo sacramental, aun conllevando la condena social impartida por la comunidad no implicaban sanciones coercitivas institucionalizadas que reasegurasen el cumplimiento de lo ideológicamente prescrito en el propio sistema relacional. Si en algunos de los vínculos así configurados encontrábamos no obstante la presencia

${ }^{58}$ Véase Barriera y Tarragó, "Elogio”, 2003, p. 193. 


\section{CUADRO 5. DISTRIBUCIÓN DE LOS DEUDORES SEGÚN SU UBICACIÓN RELACIONAL (EN PORCENTAJES)}

\section{Ubicación}

relacional de

los deudores

\author{
Distribución de los deudores \\ Roxas y Azevedo Tapia de Vargas
}

Porcentaje sobre valor acreditado Roxas y Azevedo Tapia de Vargas
Nivel 1

9

Nivel 2

Nivel 3

Total
24

67

100
8

29

63

100
5

43

52

100
5

54

100

Nota: en el nivel 1 se ubican los deudores notariados con los cuales los acreedores sostuvieron asimismo lazos de parentesco ritual (deudores que participan en el círculo primario de sociabilidad del acreedor); en el nivel 2 se ubican los deudores con los cuales los acreedores sostuvieron lazos secundarios (deudores que participan en el círculo secundario de sociabilidad del acreedor); en el nivel 3 se ubican aquellos deudores sobre los cuales no hay registro de otro tipo de contactos, previos ni posteriores, con el acreedor por fuera del lazo crediticio formal.

Fuente: elaboración propia con base en AGN, sala IX, Escribanías antiguas, tt. V-XXVII.

de contratos ejecutables, como las escrituras notariales que formalizaban las deudas, esa intersección era sin embargo minoritaria, tanto en relación con el conjunto de lazos espirituales detentados por el acreedor (Tapia formalizaba sus créditos con 15\% de las personas con las que se emparentaba ritualmente y Roxas con sólo 3\% de ellas) como en relación con el conjunto de operaciones de crédito formalizado, como mencionamos más arriba. Esto nos permite ratificar que la formalización del contrato ejecutable ante el notario constituyó una práctica instrumentada por el acreedor para operar y negociar por fuera de esas tramas íntimas de lazos interpersonales o en los límites de las mismas, cuando los grados de proximidad ya no eran suficientes para sostener los tratos en la confianza, o cuando la proximidad y su confianza estaban debilitadas, preñadas de tensiones o recelos.

\section{CONCLUSIONES}

Los actores del temprano Buenos Aires disponían de una estructura contractual con la cual configurar legalmente sus transacciones. Los contratos analizados se apoyaban muy exiguamente en los lazos de parentesco y movilizaban en su conjunto un capital considerable. Ni prescindibles ni marginales, estas transacciones se ubicaron en los márgenes o por fuera de las redes de relaciones interpersonales que constituían los círculos primarios de sociabilidad de los actores. 


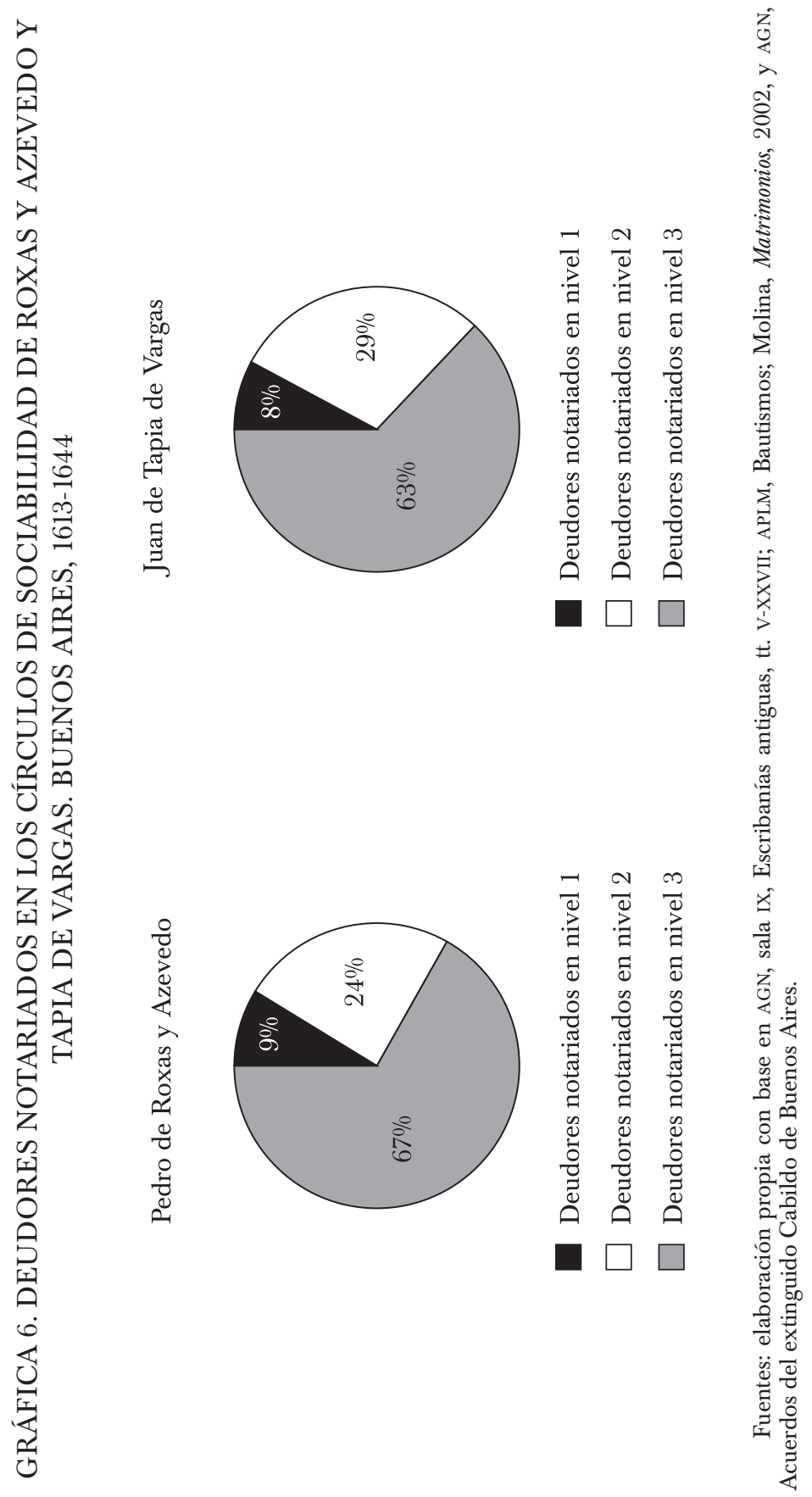


Los montos medios acreditados, los plazos estipulados y el destino económico asignado a buena parte de las obligaciones y deudas muestran que estas escrituras permitían articular el anticipo a crédito de mercancías y esclavos, dinamizar el segmento de consumo que requería pago en metálico (mediante préstamos destinados al avío, a gastos de viajes, a despachos, o a la adquisición de mercancías) y lubricar, en suma, los mecanismos capilares de la interacción económica (como queda expresado en el crédito destinado a saldar deudas previas, o en las ventas a crédito de bienes muebles e inmuebles).

De ello se desprende que el grueso de estos contratos no estructuraba tanto la organización central de las empresas como las transacciones que tenían lugar en los diversos eslabones de su subsiguiente realización económica. Los cambios de manos se multiplicaban a pequeña escala, dentro de la comarca y hacia fuera de la misma, y las operaciones que los constituían demandaban diversas prácticas de crédito para vender, consignar o saldar pagos. Para este universo de transacciones, los círculos sociales primarios se revelaban relativamente exiguos, conduciendo a los actores a interactuar económicamente a través de entornos relacionales más distantes y arriesgados.

En esta instancia de la interacción económica, en la que podían intervenir desde reconocidos vecinos y grandes comerciantes organizadores de empresas, hasta tratantes ocasionales y mercaderes itinerantes, la familia y el parentesco cedían al escribano público su papel como articuladores de la interacción. Cuando el deudor era desconocido para el acreedor o cuando el conocimiento interpersonal entre ambos no bastaba para librar el trato a arreglos y arbitrajes privados, los actores apelaban al dispositivo institucional provisto por el escribano. ${ }^{59}$ No eran estos unos contratos tácitos establecidos en el interior de un tejido confiable de vínculos primarios y con arreglo a una normatividad interna: eran verdaderos compromisos escritos, ordenados por leyes que trascendían singularidades interpersonales. ${ }^{60}$

Si el compadrazgo sacramental también se revelaba como un dispositivo institucional con el cual enfrentar los riesgos del oportunismo, dicho mecanismo presuponía la ubicación del lazo en el seno de una comunidad

${ }^{59}$ Los diversos lazos fundados en la afinidad o en las lealtades corporativas ofrecerían a los actores la posibilidad de entablar por sí mismos los vínculos, "relying on networks of neighbors, relatives, or friends from the same métier. Those who wanted to lend found trustworthy borrowers within the same family, neighborhood, or profession. They had no need of the notary, who added little to the financial transaction besides drawing up the loan documents and preserving the necessary copies." Hoffman, Postel-Vinay y Rosenthal, "Information", 1999, p. 81. Este universo contractual discurría, en efecto, por fuera o en los límites de los círculos de sociabilidad confiables de los actores.

${ }^{60}$ Véase Moutoukias, “Contrabandistas”, s. a., p. 15. 
que lo reconociese públicamente y lo regulase, no podían los acreedores asegurarse el cumplimiento de las obligaciones asumidas por sus deudores mediante semejante mecanismo reputacional de sanciones cuando el trato entre ambos no se concertaba dentro de una comunidad o trama de reconocimientos interpersonales, proveedora de densos circuitos informacionales que constriñeran la conducta ${ }^{61}$ Como hemos observado, la vulnerabilidad de las identidades y la transgresión de la legalidad determinaban el terreno sobre el cual los acreedores arriesgaban sus valores ante personajes cuya reputación personal y crediticia no siempre tenían oportunidad de conocer. El instrumento contractual ofrecido por el escribano se revelaba, entonces, menos dependiente de arreglos sostenidos en la infrajusticia o arbitrajes dirimidos sobre una tácita normatividad interna, a la vez que articulaba la transacción sobre un orden normativo más ubicuo, que trascendía el límite de una comunidad.

De este modo, el contrato notarial se presentaba a los actores como un dispositivo institucional que podía sustituir al parentesco cuando los lazos interpersonales eran débiles o inexistentes, instituidos con personajes externos o en los márgenes de los círculos sociales primarios. Aun implicando mayores costos de transacción en términos económicos, el contrato notariado sustituía al parentesco como dispositivo institucional para concretar la interacción económica con personajes relacionalmente distantes y, así, lo complementaba. La importancia de este dispositivo contractual y de las transacciones extrarreticulares que el mismo permitía concretar, queda constatada en la magnitud alcanzada por el endeudamiento escriturado durante el periodo.

Sin embargo, la sumisión del deudor a "qualesquier juezes y justiçias de su magestad" (tal como habitualmente quedaba establecido en el contrato) no constituía por sí misma una garantía de previsión que moviese al acreedor a escriturar la deuda. Aunque mínima, la confianza era ineluctable. Si la escritura consistía en un elemento probatorio y, por ello, condición necesaria para iniciar un proceso ejecutivo por cauces legales, lo endeble de las instituciones destinadas a garantizar la ejecución de los contratos tornaba a la escrituración una condición insuficiente para garantizar la previsión. Era la capacidad de acción (o poder) del acreedor la que podía ofrecerle recaudos y garantías firmes al momento de arriesgarse anticipando valores a sujetos externos a los círculos confiables. Esa capacidad de

${ }^{61}$ Una fluida circulación informacional dentro de la red (como la que es viable encontrar en una comunidad) contribuye a disminuir el riesgo de cooperación, mecanismo reputacional de sanciones que no sería viable ejercer en estructuras abiertas. En la disminución de ese riesgo aparece la ventaja principal del mecanismo reticular que Burt concibe como closure y sobre el cual se asienta la capacidad del compadrazgo como institución aseguradora del cumplimiento de los tratos. Véase Burt, "Social”, 2002. 
acción personal se fortalecía, por un lado, a partir de la inscripción del actor en redes interpersonales fiables, lo cual le proveía recursos relacionales susceptibles de movilización ( $\mathrm{y}$, al posicionarse favorablemente en ellas, facultades de arbitraje interno). Por otro lado, su capacidad de acción también se fortalecía mediante la obtención de cargos y oficios que le confiriesen potestades jurisdiccionales para ejercer poder desde las instituciones formalmente reconocidas. La garantía al cumplimiento de los tratos -aun los concertados por fuera de las redes confiables- recaía en la capacidad que el acreedor tuviese para hacerlos cumplir. Comprendemos entonces por qué Roxas y Tapia tuvieron la posibilidad de apelar con una frecuencia extraordinaria a este dispositivo institucional para configurar sus tratos: actores multiimplantados en una diversidad de cargos y oficios con potestad jurisdiccional y poseedores de amplios -aunque disímiles- recursos relacionales que dejaron su rastro en el capital social constituido por sus compadres, tenían asimismo la posibilidad de emplear aquella multitud de lazos débiles constituida por sus deudores notariados como una potencial fuente de recursos relacionales, evaluando el comportamiento de los deudores con el recaudo contractual para, oportunamente, incorporarlos a círculos próximos y retroalimentar así su capital social.

No obstante, el poder o capacidad de acción del acreedor sólo podía practicarse legítimamente si se ejercía con arreglo al orden normativo en que se inscribía su lazo con el deudor. Así, mientras el compadrazgo oficiaba como institución que legitimaba las obligaciones y responsabilidades en los círculos de sociabilidad próximos, era la ley escrita en contratos notariados la que oficiaba como institución que legitimaba las obligaciones por fuera o en los límites de los círculos de sociabilidad próximos. Tanto en el interior de los círculos próximos de sociabilidad como por fuera de los mismos, los actores debían institucionalizar su capacidad de acción para volverla legítima.

Las redes de parentesco y los contratos notariales constituyeron órdenes institucionales alternativos, sustitutivos y complementarios, para el despliegue de la interacción económica. Dado un contexto adverso, las transacciones crediticias en el temprano Buenos Aires se llevaron adelante con una fuerte apelación a los instrumentos económicamente más costosos, aunque institucionalmente mejor adecuados. Articulados por el despacho notarial antes que por las tramas del parentesco. Las operaciones legalmente escrituradas constituyeron una red más allá de las redes y en el centro de la economía. 


\section{FUENTES CONSULTADAS}

\section{Archivos}

AGN Archivo General de la Nación, Buenos Aires, Argentina.

APLM Archivo Parroquial de Nuestra Señora de la Merced, Buenos Aires, Argentina.

\section{Bibliografía}

ACARETte Du Biscay, Relación de un viaje al Río de la Plata y de allí por tierra al Perú. Con observaciones sobre los habitantes, sean indios o españoles, las ciudades, el comercio, la fertilidad y las riquezas de esta parte de América, trad. Francisco Fernández Wallace y pról. Julio César González, Buenos Aires, Alfer \& Vays, 1943 [1663], 132 pp.

Alfani, Guido, 'Reformation, 'Counter-reformation' and Economic Development from the Point of View of Godparenthood: an Anomaly? (Italy and Europe, 14th19th centuries)" en Francesco Ammannati (ed.), Religione e istituzioni religiose nell' economia europea. 1000-1800, Florencia, Firenze University Press, 2012, pp. 477-490. y Vincent Gourdon, "Entrepreneurs, Formalisation of Social Ties and Trustbuilding in Europe (14th-20th centuries)" en <www.dondena.unibocconi.it/ wp25>, Milán, Università Bocconi, marzo 2010, Dondena Working Papers núm. 25. [Consulta: 18 de mayo de 2012.]

Álvarez-Nogal, Carlos, "Mercados o redes de mercaderes: el funcionamiento de la feria de Portobelo" en Nikolaus Böttcher, Bernd Hausberger y Antonio IBARRA (coords.), Redes y negocios globales en el mundo ibérico, siglos XVI-XVIII, México, Madrid y Frankfurt, El Colegio de México/Iberoamericana/Vervuert, 2011, pp. 53-86.

Andrien, Kenneth, "The Sale of Juros and the Politics of Reform in the Viceroyalty of Perú, 1608-1695", Journal of Latin American Studies, Cambridge University Press, vol. 13, núm. 1, 1981, Cambridge, pp. 1-19.

Archivo General de la Nación, Reales cédulas y provisiones. 1517-1662, Buenos Aires, Talleres Gráficos de la Penitenciaría Nacional, 1911, t. I.

Barral, María Elena, “¿ ¿Voces vagas e infundadas? Los vecinos de Pilar y el ejercicio del ministerio parroquial, a fines del siglo XVIII", Sociedad y Religión, Centro de Estudios e Investigaciones Laborales, núms. 20-21, 2000, Argentina, pp. 77-114.

BARriera, DARÍo y Griselda TARRAGÓ, "El vínculo y la posibilidad-práctica mercantil, construcción de vínculos sociales y factores de riesgo (Santa Fe, siglo XVIII)", Primeras Jornadas de Historia Regional Comparada, Porto Alegre, 2000.

"Elogio de la incertidumbre. La construcción de la confianza: entre la previsión y el desamparo (Santa Fe, Gobernación de Río de la Plata, siglo XVIII)", Revista de Historia, Universidad Nacional/Universidad de Costa Rica, núm. 48, 2003, Costa Rica, pp. 183-223. 
Bertrand, Michel, "De la familia a la red de sociabilidad", Revista Mexicana de Sociología, Universidad Nacional Autónoma de México, vol. 61, núm. 2, 1999, México, pp. 107-135.

"Del actor a la red: análisis de redes e interdisciplinaridad", Nuevo Mundo Mundos Nuevos, Coloquios, 2009, <http://nuevomundo.revues.org/index57505. html $>$. [Consulta: 1 de diciembre de 2009.]

Birocco, CARLOS, "El ganado cimarrón en Buenos Aires: poder y vecindad en la explotación de un recurso (1650-1720)", IIIJornadas de Historia Agraria, Buenos Aires, Fondo de Cultura Económica/Universidad de Buenos Aires, 2003.

Bourdieu, Pierre, "The Forms of Capital" en Mark Granovetter y Richard Swedberg (eds.), The Sociology of Economic Life, Colorado y Oxford, Westview Press, 2001.

Burt, Ronald, "The Social Capital of Structural Holes" en Mauro Guillén et al. (eds.), The New Economic Sociology. Developments in an Emerging Field, Nueva York, Russell Sage Foundation, 2002.

Ceballos, Rodrigo, "Arribadas portuguesas. A participação luso-brasileira na consituição social de Buenos Aires (c. 1580-c. 1650)", tesis de doctorado, Brasil, Universidade Federal Fluminense, 2008.

COMADRÁN RuIz, JORGE, Evolución demográfica argentina durante el periodo hispano (15351810), Buenos Aires, Editorial Universitaria de Buenos Aires, 1969.

Fradkin, Raúl y Juan Carlos Garavaglia, La Argentina colonial. El Río de la Plata entre los siglos XVI y XIX, Buenos Aires, Siglo XXI, 2009.

Gelman, Jorge, "Economía natural-Economía monetaria. Los grupos dirigentes de Buenos Aires a principios del siglo XVII", Anuario de Estudios Americanos, Escuela de Estudios Hispano-Americanos de Sevilla, núm. 44, 1987, España, pp. 89-107.

González Lebrero, Rodolfo, La pequeña aldea. Sociedad y economía en Buenos Aires (1580-1640), Buenos Aires, Biblos, 2002.

Granovetter, Mark, "La fuerza de los lazos débiles. Revisión de la teoría reticular" en Félix Requena Santos, Análisis de redes sociales. Orígenes, teorías y aplicaciones, Madrid, Centro de Investigaciones Sociológicas/Siglo XXI, 2003.

Herzog, TAmar, Mediación, archivos y ejercicio. Los escribanos de Quito (siglo XVII), Fráncfort del Meno, Vittorio Klostermann, 1996.

Hoffman, Philip, Gilles Postel-Vinay y Jean-Laurent Rosenthal, "Information and Economic History: How the Credit Market in Old Regime Paris Forces Us to Rethink the Transition to Capitalism", The American Historical Review, Asociación Americana de Historia, vol. 104, núm. 1, 1999, Bloomington, pp. 69-94.

Johnson, Lyman y Sonya Lipsetr-Rivera (eds.), The Faces of Honor. Sex, Shame and Violence in Colonial Latin America, Albuquerque, University of New Mexico Press, 1998.

Jumar, Fernando, "Le commerce atlantique au Río de la Plata, 1680-1778”, tesis de doctorado, Francia, École des Hautes Études en Sciences Sociales, 2000. 
KICZA, John, Empresarios coloniales. Familias y negocios en la ciudad de México durante los Borbones, México, Fondo de Cultura Económica, 1986.

Kraselsky, Javier G., "De las Juntas de Comercio al Consulado. Los comerciantes rioplatenses y sus estrategias corporativas, 1779-1794", Anuario de Estudios Americanos, Escuela de Estudios Hispano-Americanos de Sevilla, vol. 64, núm. 2, 2007, España, pp. 145-170.

LANGUe, FrÉderiQUe, "Las elites en América española. De la historia de las prácticas a la práctica de la historia”, Anuario del Instituto de Estudios Histórico-Sociales, Universidad Nacional del Centro de la Provincia de Buenos Aires, núm. 15, 2000, Tandil, pp. 101-116.

LATZINA, FRANCISCO, "El comercio argentino antaño y hogaño" en Censo agropecuario nacional. La ganadería y la agricultura en 1908, Buenos Aires, Oficina Meteorológica Argentina, 1909, vol. III.

LeVI, Giovanni, La herencia inmaterial. La historia de un exorcista piamontés del siglo XVII, Madrid, Nerea, 1985.

Levillier, Roberto, La audiencia de charcas. Correspondencia de presidentes y oidores, documentos del Archivo de Indias, Madrid, J. Pueyo, 1918-1922, t. III.

LindLEY, RiCHARD, Kinship and Credit in the Structure of Guadalajara's Oligarchy, 18001830, Austin, University of Texas, 1976.

Martínez López-Cano, María del Pilar, "Mecanismos crediticios en la ciudad de México en el siglo XVI” en LeOnOr Ludlow y Jorge Silva RiQuer (comps.), Los negocios y las ganancias de la colonia al México moderno, México, Instituto de Investigaciones Dr. José María Luis Mora/Universidad Nacional Autónoma de México, 1993.

La génesis del crédito colonial. Ciudad de México, siglo XVI, México, Universidad Nacional Autónoma de México, 2001.

Mata DE LÓPEZ, SARA E., "El crédito mercantil en Salta a fines del siglo XVIII", Anuario de Estudios Americanos, Escuela de Estudios Hispano-Americanos de Sevilla, vol. 53, núm. 2, 1996, España, pp. 147-171.

Molina, Raúl, Matrimonios, bautismos y defunciones de la catedral de Buenos Aires, 16011644. Y legajos I y II de expedientes matrimoniales del archivo del Arzobispado de Buenos Aires (ex curia eclesiástica), Buenos Aires, Academia Americana de Genealogía, 2002.

Moutoukias, Zacarías, Contrabando y control colonial en el siglo XVII. Buenos Aires, el Atlántico y el espacio peruano, Buenos Aires, Centro Editor de América Latina, 1988, 217 pp.

"Una forma de oposición: el contrabando" en MASSIMO GANCI y RUGGIERO Romano (eds.), Governare il mondo. L'imperio spagnolo dalx XV al XIX secolo, Palermo, Società Siciliana per la Storia Patria/Instituto di Storia Moderna, 1991.

"Redes personales y autoridad colonial. Los comerciantes de Buenos Aires en el siglo XVIII", Annales. Histoire, Sciences Sociales, École des Hautes Études en Sciences Sociales, núms. 4-5, 1992, Francia, pp. 889-915, trad. María Carolina 
Zapiola para la Cátedra de Historia de América II (Colonial), Facultad de Filosofía y Letras, Universidad de Buenos Aires.

, "Familia patriarcal o redes sociales: balance de una imagen de la estratificación social”, Anuario del Instituto de Estudios Histórico-Sociales, Universidad Nacional del Centro de la Provincia de Buenos Aires, núm. 15, 2000, Tandil, pp. 133-151. “¿Por qué los contrabandistas no hacen trampa?: Redes sociales, normas y empresa en una economía de no mercado (el Río de la Plata en la segunda mitad del siglo XVIII)", mimeo., s. a.

ReITANO, Emir, "Los portugueses del Buenos Aires tardocolonial: inmigración, sociedad, familia, vida cotidiana y religión", tesis de doctorado, Argentina, Universidad Nacional de La Plata, 2003.

Requena SAntos, FÉlix, "El concepto de red social”, Reis: Revista Española de Investigaciones Sociológicas, Centro de Investigaciones Sociológicas, núm. 48, 1989, España, pp. 137-152.

Saguier, Eduardo R., "Economic Impact of Commercial Capital on Credit Transactions: Buenos Aires in the Early Seventeenth Century", Anuario de Estudios Americanos, Escuela de Estudios Hispano-Americanos de Sevilla, núm. 44, 1987, España, pp. 109-139.

Scheuss de Studer, Elena, La trata de negros en el Río de la Plata durante el siglo XVIII, Buenos Aires, Universidad de Buenos Aires, 1958.

Simmel, GeOrg, Sociología. Estudios sobre las formas de socialización, Madrid, Alianza Editorial, 1986, vol. II.

SuÁrez, Margarita, Desafíos transatlánticos: mercaderes, banqueros y el Estado en el Perú virreinal, 1600-1700, Lima, Pontificia Universidad Católica del Perú/Instituto Riva-Agüero/Fondo de Cultura Económica/Instituto Francés de Estudios Andinos, 2001.

Trelles, Manuel Ricardo, Registro estadístico de Buenos Aires 1865, Buenos Aires, El Nacional, 1867, vol. II. , Registro estadístico de Buenos Aires 1866, Buenos Aires, El Porvenir, 1869, vol. II.

Trujillo, Oscar, "Facciones, parentesco y poder: La elite de Buenos Aires y la rebelión de Portugal de 1640" en Bartolomé Yun Casalilla (dir.), Las redes del imperio: elites sociales en la articulación de la monarquía hispánica, 1492-1714, Madrid, Universidad Pablo de Olavide/Marcial Pons, 2009.

VALLADARES RAMíREZ, RAFAEL, "El Brasil y las Indias españolas durante la sublevación de Portugal (1640-1688)”, Cuadernos de Historia Moderna, núm. 14, 1993, España, pp. 151-172.

Valle Pavón, Guillermina del, "Comercio y política, el Consulado de México en la época de los Habsburgo" en Héctor Noejovich (ed.), América bajo los Austrias: economía, cultura y sociedad, Lima, Pontificia Universidad Católica del Perú, 2001, pp. 273-296. 
"Relaciones de negocios, familiares y de paisanaje de Manuel Rodríguez de Pedroso, conde de San Bartolomé de Xala, 1720-1770" en Antonio Ibarra y Guillermina del VAlle Pavón (coords.), Redes sociales e instituciones comerciales en el imperio español, siglos XVII a XIX, México, Instituto de Investigaciones Dr. José María Luis Mora, 2007, pp. 117-140.

Vila Vilar, Enriqueta, Hispanoamérica y el comercio de esclavos. Los asientos portugueses, Sevilla, Escuela de Estudios Hispano-Americanos/Consejo Superior de Investigaciones Científicas, 1977.

WAsserman, Martín L. E., "Esclavos desaparecidos. La invisibilización jurídica de los hombres y mujeres comercializados durante el temprano siglo XVII en Buenos Aires" en Florencia Guzmán y Lea Geler (coords.), Actas de las Segundas Jornadas de Estudios Afrolatinoamericanos del Grupo de Estudios Afrolatinoamericanos, Buenos Aires, Universidad de Buenos Aires/Mnemosyne, 2011, pp. 817-831.

Wobeser, Gisela von, "Mecanismos crediticios en la Nueva España. El uso del censo consignativo", Mexican Studies/Estudios Mexicanos, Universidad de California, vol. 5, núm. 1, Estados Unidos, 1989, pp. 1-23.

ZúNiga, JEAN-PAUL, "Clan, parentela, familia, individuo: ¿qué métodos y qué niveles de análisis?”, Anuario del Instituto de Estudios Histórico-Sociales, Universidad Nacional del Centro de la Provincia de Buenos Aires, núm. 15, Tandil, 2000, pp. 51-60. 